\title{
The role of cognitive abilities in decisions from experience: Age differences emerge as a function of choice set size
}

\author{
Renato Frey ${ }^{\mathrm{a}, \mathrm{b}, *}$, Rui Mata ${ }^{\mathrm{a}, \mathrm{b}}$, Ralph Hertwig ${ }^{\mathrm{b}}$ \\ ${ }^{a}$ University of Basel, Department of Psychology, Cognitive and Decision Sciences, Missionsstrasse 64A, CH-4055 Basel, Switzerland \\ ${ }^{\mathrm{b}}$ Max Planck Institute for Human Development, Center for Adaptive Rationality, Lentzeallee 94, DE-14195 Berlin, Germany
}

\section{A R T I C L E I N F O}

\section{Article history:}

Received 26 February 2015

Revised 4 May 2015

Accepted 5 May 2015

\section{Keywords:}

Decisions from experience

Risky choice

Information sampling

Cognitive modeling

Cognitive abilities

Aging

\begin{abstract}
A B S T R A C T
People seldom enjoy access to summarized information about risky options before making a decision. Instead, they may search for information and learn about environmental contingencies-thus making decisions from experience. Aging is associated with notable deficits in learning and memory-but do these translate into poorer decisions from experience? We report three studies that used a sampling paradigm to investigate younger ( $M=24$ years) and older $(M=71$ years $)$ adults' decisions from experience. In Study $1(N=121)$ participants made 12 decisions between pairs of payoff distributions in the lab. Study 2 $(N=70)$ implemented the same paradigm using portable devices, collecting 84 decisions per individual over a week. Study $3(N=84)$ extended the sampling paradigm by asking participants to make 12 decisions between two, four, and eight payoff distributions (in the lab). Overall, the behavioral results suggest that younger and older adults are relatively similar in how they search and what they choose when facing two payoff distributions (Studies 1 and 2). With an increasing number of payoff distributions, however, age differences emerged (Study 3). A modeling analysis on the level of individual participants showed that a simple delta-learning rule model best described the learning processes of most participants. To the extent that ongoing updating processes unfold relatively automatically and effortlessly, older adults may be liberated from the detrimental consequences of cognitive aging in the case of decisions from experience with few decision options. We discuss implications for research on decisions from experience and choice performance over the lifespan.
\end{abstract}

(c) 2015 Elsevier B.V. All rights reserved.

\section{Introduction}

Who runs the world? The average age of the 72 people in Forbes' 2013 ranking of the World's Most Powerful People is 61 years (Howard, 2013). Relatively old individuals thus wield enormous political and economic power worldwide. As populations across the globe age, the selection of older individuals into such powerful roles may be further

\footnotetext{
* Corresponding author at: University of Basel, Department of Psychology, Cognitive and Decision Sciences, Missionsstrasse 64A, CH-4055 Basel, Switzerland.

E-mail address: renato.frey@unibas.ch (R. Frey).
}

intensified. For instance, the average age of members of U.S. Congress has risen almost steadily since the 1980s in tandem with demographic aging ("The capitol's age pyramid: A graying congress," 2010). Given that aging is associated with decline in many cognitive abilities (Li et al., 2004; Nilsson et al., 2004; Schaie, 2012), the question arises: How does older adults' decision making fare relative to that of younger adults?

There is not yet a conclusive answer. Some have argued that, despite cognitive decline and loss in computational power, the aging brain becomes more effective in its ability to recognize patterns ("wisdom"; Goldberg, 1970), but others have observed that "just as elders show profound 
declines in cognitive function, they also show profound declines in choice rationality" (Tymula, Rosenberg Belmaker, Ruderman, Glimcher, \& Levy, 2013, p. 1; see also Denburg, Tranel, \& Bechara, 2005). Still others have concluded that the decision-making performance of older and younger people is comparable (e.g., Kovalchik, Camerer, Grether, Plott, \& Allman, 2005) and that older people are sometimes even "less biased than the younger individuals" (p. 79). As various researchers have pointed out, the trite truth seems to be that more research is required (Kovalchik et al., 2005; Mata, Josef, Samanez-Larkin, \& Hertwig, 2011; Tymula et al., 2013). More importantly, and as we argue below, researchers have to go beyond blanket statements concerning the role of aging in decision making and instead consider the role of the properties and demands of the choice environment in determining the successes or failures of older adults' decision making. In other words, the task ahead is to investigate whether and how particular task characteristics lead to age differences in decision making.

One crucial issue with regard to the decision-making faculties of older people is their ability to deal with risk and uncertainty-a ubiquitous challenge in the process of making decisions. Information about the probabilistic structure of choice options can be acquired in at least two ways. In some contexts, people can rely on summary descriptions of risky prospects. For example, weather forecasts explicitly state a probability of rain, snowfall, or hurricane landfall at a given location; likewise, drug package inserts describe the risks and side effects of the medication in plain terms. Equipped with such quantified risk information, people can make decisions from description (Hertwig, Barron, Weber, \& Erev, 2004). Such information is, however, restricted to those domains in which tabulated risks exist. More often, people have to navigate the perils and opportunities of the modern world without transparent and convenient descriptions of risks. Many consequential decisions-including health care choices, intergenerational transfers (e.g., Coall \& Hertwig, 2010), personal spending, and everyday risks (e.g., driving in bad weather; crossing a busy street)-are made without full knowledge of the possible outcomes and their probabilities. In this twilight of uncertainty, people may explore the current environment to determine its risks and opportunities. Equipped with such experiences of risks, people can make decisions from experience (Hertwig et al., 2004).

\subsection{Decisions from experience and cognitive aging}

A fundamental building block of decisions from experience is information search. Ceteris paribus, the more a person searches (explores), the better her estimate of an option's value (Hertwig \& Pleskac, 2010). Reliance on small samples can prompt systematically higher or lower levels of risk taking relative to those observed in decisions from description (in which outcomes and probabilities are explicitly presented, as in the traditional gambling tasks ubiquitously investigated by psychologists and economists). One reason is that small samples may not include rare but highly consequential events and, if they do, they may underrepresent them. Depending on whether these rare events are desirable or undesirable, experienced-based choice will involve either more or less risk aversion relative to description-based choice (see Fig. 2 in Hertwig and Erev (2009)).

To date, little is known about the cognitive demands people face when they explore and learn about decision options-and the extent to which these processes are affected by cognitive aging. Arguably, the mind's most notable transformation across the life span is a substantial decline in fluid cognitive abilities (e.g., Park et al., 2002). This inevitable decline hampers older adults' processing speed and working memory capacity, as well as their short-term memory capacity-all components potentially involved in search and learning processes. Indeed, a recent meta-analysis on age differences in risky choice reported small to medium effect sizes in various experience-based tasks (but not in most description-based tasks; Mata et al., 2011), suggesting that age-related differences in risk taking might be a function of decreased learning performance (see also Eppinger, Hämmerer, \& Li, 2011; Marschner et al., 2005; Zamarian, Sinz, Bonatti, Gamboz, \& Delazer, 2008). Specifically, the direction of the age differences varied across experience-based tasks: In tasks that required decision makers to learn to take less risk (in order to make better decisions), older adults proved to be more risk taking than younger adults; conversely, in tasks that required decision makers to learn that they should take more risks, older adults were less prone to risk taking than their younger counterparts.

Relatedly, a meta-analysis on predecisional information search suggests that older adults tend to look up less information before making a decision and this decrease is particularly evident when many pieces of information are presented (Mata \& Nunes, 2010; see also Mata, Schooler, \& Rieskamp, 2007). Similarly, Spaniol and Wegier (2012) asked younger and older adults to make decisions from experience using a sampling paradigm and found that older adults sampled slightly less from the payoff distribution than did younger adults. Although Spaniol and Wegier did not explore the extent to which sampling or information integration were related to individual differences in cognitive ability or other variables, two other investigations of decisions from experience involving younger adults observed small correlations $(r \approx .2)$ between search effort and measures of fluid cognitive abilities (Rakow, Demes, \& Newell, 2008; Rakow, Newell, \& Zougkou, 2010).

Some studies on multi-attribute decision making suggest that older adults tend to use simplifying strategies in the process of integrating information (Mata et al., 2007), sometimes even in the absence of significant age differences in search effort (Mata, von Helversen, \& Rieskamp, 2010). For example, ongoing updating processes (of frequencies of occurrences or of sample means) seem to unfold relatively automatically and effortlessly (Hasher \& Zacks, 1984). That is, under the assumption that people can make use of simplifying strategies, one might not expect decisions from experience between only a few decision options to be cognitively taxing. Consequently, age differences in decisions from experience may not be observed across the board. Rather, older adults' declining fluid abilities may only lead to differences in search and 
choice under circumstances of information overload; that is, when a person has to keep track of multiple choice dimensions, outcomes, or decision options in parallel.

\subsection{Overview of studies}

Most previous studies on age differences in experience-based tasks have used rather complex paradigms involving several options and/or trade-offs between exploration and exploitation (i.e., the possibility of learning about vs. choosing between options; Iowa Gambling Task, Bechara, Damasio, Damasio, \& Anderson, 1994; Balloon Analogue Risk Task, Lejuez et al., 2002). This renders it difficult to assess the role of particular task characteristics on individual and age differences in decision making. Therefore, we used a simpler sampling paradigm to investigate the extent to which decisions from experience tap into fluid cognitive abilities-and in particular, under which conditions younger and older adults' decisions from experience differ. Specifically, we adopted a sampling paradigm that strictly separates exploration from exploitation, thus allowing us to distinguish between different decision-making processes (e.g., Hertwig et al., 2004; Weber, Shafir, \& Blais, 2004; for a review of related paradigms, see Hertwig \& Erev, 2009). Our approach was to use different parameterizations of this paradigm to vary the complexity of the choice ecology. Depending on the latter, declining fluid abilities may or may not lead to age differences in different building blocks of decisions from experience-such as search effort or information encoding and integration. We thus aimed to investigate both the variants as well as the invariants of younger and older adults' decisions from experience in different choice ecologies. "Progress in science often comes from discovering invariances in relationships among variables" (Rouder, Speckman, Sun, Morey, \& Iverson, 2009, p. 225), and we believe this is particularly true for a better understanding of the cognitive demands required in decisions from experience. Examining which of the building blocks of decisions from experience are (not) subject to cognitive aging will not only permit us to derive implications for older adults' everyday decision making but also lead to a better understanding of the cognitive processes involved in decisions from experience, in general. To study both the variants and invariants of younger and older adults' decisions from experience, we relied on Bayesian statistics. A Bayesian approach permits quantifying the evidence not only for differences between groups but also for the Null; that is, that there truly is no difference between groups (Kruschke, 2011; Morey \& Rouder, 2011; Rouder et al., 2009).

In Study 1, we used a simple version of the sampling paradigm to compare younger and older adults' information search and choices in decisions from experience (in both gain and loss domains). In Study 2, we varied payoff distributions and took advantage of mobile devices to elicit a large number of decisions from experience from each individual, thus permitting us to model the cognitive processes underlying each of younger and older individuals' learning and decision making. Finally, in Study 3 we increased the number of available decision options to investigate the role of a more demanding choice environment on search and choice. All studies included a set of individual difference measures-most importantly, fluid cognitive abilitieswhich made it possible to link individual characteristics to decision behavior (see Section 5 below).

\section{Study 1: Are there age-related differences in information search and choice?}

As a starting point, we used the classic sampling paradigm (Hertwig \& Erev, 2009) with two decision options to study younger and older participants' decisions from experience in both gain and loss payoff distributions. A crucial feature of the sampling paradigm is that it strictly separates the learning stage from the final decision. Unlike in other paradigms, participants first have the opportunity to explore the payoff distributions for as long as they like and without the potential interference of simultaneously making consequential decisions. It thus permits a direct examination of whether and how cognitive aging translates into effects on information search and learning.

\subsection{Method}

\subsubsection{Participants}

We recruited two groups of participants from the subject pool database of the Department of Psychology at the University of Basel: 60 younger adults ( 46 female) aged 18 to 30 years $(M=23.6, S D=3.1)$ and 61 older adults ( 32 female) aged 63 to 88 years $(M=71.3, S D=6.4)$; further sociodemographic characteristics are listed in Table 1. Participants received a fixed fee of 25 Swiss francs (CHF; approx. 27.4 USD) plus a performance-contingent bonus based on their choices.

\subsubsection{Procedure and decision problems}

Participants were tested individually. They first read instructions detailing the task, the procedure, and payoffs. They then completed two practice trials in which they familiarized themselves with the computer and with the sampling and decision stage of the task (Fig. 1) before responding to 12 decision problems (Table 2). For comparability with past research, we used the six decision problems from Hertwig et al. (2004). In addition, we reflected those problems that were previously studied only in the gain domain into the loss domain, and included two new gain problems (and their loss equivalents) with similar characteristics (e.g., existence of rare events).

In each decision problem, participants could first learn about the payoff distributions of the two available options by sampling from them (i.e., clicking on the boxes; Fig. 1) as often as they liked, with no consequences for their final payoff. Once they stopped search, they pressed a "decision button" and indicated their final choice. This resulted in a consequential random draw of an outcome from the respective payoff distribution. Only after completing all decision trials did participants receive feedback concerning their overall payoff, which was a random draw from the chosen payoff distribution in one of the 6 decision 
Table 1

Mean (SD) participant characteristics and statistics for the effects of age group in Study 1.

\begin{tabular}{|c|c|c|c|c|c|}
\hline \multirow[t]{2}{*}{ Characteristic } & \multicolumn{2}{|c|}{ Age group } & \multicolumn{3}{|c|}{ Statistic } \\
\hline & Young & Old & $\Delta$ & 95\% HDI & $d$ \\
\hline$N$ & 60 & 61 & & & \\
\hline Sex (female) & $\begin{array}{l}46 \\
(77 \%)\end{array}$ & $\begin{array}{l}32 \\
(53 \%)\end{array}$ & & & \\
\hline Age & $\begin{array}{l}23.6 \\
(3.1)\end{array}$ & $\begin{array}{l}71.3 \\
(6.4)\end{array}$ & & & \\
\hline Fluid abilities & $\begin{array}{l}59.8 \\
(10.2)\end{array}$ & $\begin{array}{l}39.4 \\
(10.1)\end{array}$ & -20.4 & $\begin{array}{l}-24.2 \text { to } \\
-16.81\end{array}$ & 2.00 \\
\hline $\begin{array}{c}\text { Crystallized } \\
\text { abilities }\end{array}$ & $\begin{array}{l}31.4 \\
(2.7)\end{array}$ & $\begin{array}{l}33.6 \\
(1.6)\end{array}$ & 2.2 & 1.2 to 2.8 & 1.00 \\
\hline Numeracy & $\begin{array}{l}8.7 \\
(1.3)\end{array}$ & $\begin{array}{l}7.3 \\
(2.1)\end{array}$ & -1.4 & -2.1 to -.8 & .83 \\
\hline \multicolumn{6}{|l|}{ Education } \\
\hline $\begin{array}{c}\text { Elementary } \\
\text { school }\end{array}$ & $3(5 \%)$ & $\begin{array}{l}31 \\
(51 \%)\end{array}$ & & & \\
\hline High school & $\begin{array}{l}33 \\
(55 \%)\end{array}$ & $2(3 \%)$ & & & \\
\hline University & $\begin{array}{l}24 \\
(40 \%)\end{array}$ & $\begin{array}{l}28 \\
(46 \%)\end{array}$ & & & \\
\hline \multicolumn{6}{|l|}{ Assets } \\
\hline$<40,000 \mathrm{CHF}$ & $\begin{array}{l}50 \\
(90 \%)\end{array}$ & $5(12 \%)$ & & & \\
\hline $\begin{array}{l}40,000-80,000 \\
\text { CHF }\end{array}$ & $3(5 \%)$ & $4(9 \%)$ & & & \\
\hline$>80,000 \mathrm{CHF}$ & $3(5 \%)$ & $\begin{array}{l}33 \\
(79 \%)\end{array}$ & & & \\
\hline \multicolumn{6}{|l|}{ Debts } \\
\hline None & $\begin{array}{l}42 \\
(88 \%)\end{array}$ & $\begin{array}{l}30 \\
(64 \%)\end{array}$ & & & \\
\hline$<40,000 \mathrm{CHF}$ & $6(12 \%)$ & $6(13 \%)$ & & & \\
\hline$>40,000 \mathrm{CHF}$ & 0 & $\begin{array}{l}11 \\
(23 \%)\end{array}$ & & & \\
\hline
\end{tabular}

Note: Fluid abilities: digit-symbol substitution test (score range 0-93; Wechsler, 1981); crystallized abilities: spot-a-word (score range 0-37; Lehrl, 1977); numeracy scale (score range 0-10; Lipkus et al., 2001).

problems. At this point, they also provided demographic information and completed measures of cognitive abilities.

\subsubsection{Measures of cognitive abilities}

We used the digit-symbol substitution task (DSST; Wechsler, 1981) as a measure of fluid cognitive abilities. In addition, we used a vocabulary test (spot-a-word; Lehrl, 1977) as a measure of crystallized abilities, which tend to increase across life span (e.g., see Park et al., 2002). Finally, we also assessed participants' numerical abilities using a general numeracy scale (Lipkus, Samsa, \& Rimer, 2001). Summary statistics for these measures of cognitive abilities are listed in Table 1 and the correlations between fluid abilities and search are reported below (see Section 5). As could be expected, younger adults outperformed older adults in fluid abilities (digit-symbol substitution task) and numeracy, but not in crystallized abilities (vocabulary).

\subsection{Results and discussion}

We analyzed younger and older adults' decisions from experience on two levels, namely, search and choice. For search, we used a mixed-effects general linear model (random effects over participants with varying intercepts and slopes) with sample size (search effort) as dependent variable, and age group (younger vs. older adults), domain (gain vs. loss), and their interaction as fixed effects. Analyses were conducted in $\mathrm{R}$ version 3.0.2 ( $\mathrm{R}$ Core Team, 2014) and the MCMCglmm package for Bayesian generalized linear mixed models (Hadfield, 2010). We used a Gaussian link function for a more straightforward interpretation of the estimated coefficients but the results also hold (with one exception, see Table 3 ) for a Poisson link function (often used for count data). For choice, we used logistic regression on the option with the higher expected value ( $H$ choices) and the option with the higher experienced sample mean ( $H_{\text {exp }}$ choices), with the same predictors (age group, domain, and interaction). These models were fitted using the MCMCpack for Bayesian hierarchical binomial models (Martin, Quinn, \& Park, 2011). The results reported are robust to different parameterizations of the MCMC algorithms and based on 50,000 MCMC iterations. We refer to a "credible effect" whenever the posterior 95\% highest density interval (HDI) of an estimated parameter (e.g., the beta weights of the regression analysis) does not include 0 (cf. Kruschke, 2010). For our main independent variable "age group", we also calculated Bayes factors that indicate the evidence for the alternative (i.e., that there truly is an age difference) over the Null (i.e., that there truly is no age difference), or vice versa.

\subsubsection{Did younger and older adults' search effort differ?}

Table 3 presents the fixed-effects coefficients estimated in the mixed-effects general linear model that was used to analyze search. On average, younger adults sampled 32 times in the gain domain and 30 times in the loss domain, whereas older adults sampled 28 times in the gain domain and 27 times in the loss domain (Fig. 2). Older individuals' search effort (in terms of sample size) was thus slightly but not credibly smaller (Table 3 ). Yet, the HDI was not perfectly centered around 0 (mainly due to one outlier in the older age group who sampled over 100 times, on average), and the Bayes factor analysis suggested that it was 6.4 times more likely that there truly was an age difference in search effort than there was no such difference. This tendency of older adults to take smaller samples did affect their likelihood of experiencing rare events (i.e., events occurring with a probability <.2; see Hertwig et al., 2004) relative to younger adults: The latter experienced the rare event at least once in $77 \%$ of the decision problems whereas the older adults experienced the rare event in only $63 \%$ of the decision problems. According to a Bayesian $t$ test (Kruschke, 2013), the mean difference of 14\% (95\% HDI: 5.4 to $22.2 \%$ ) constituted a credible effect with an effect size of .61 (for results by decision problem, see Table 2). Search effort did not differ as a function of gain/loss domain (see Lejarraga, Hertwig, \& Gonzalez, 2012) or of the interaction of domain and age group (Table 3).

\subsubsection{Did younger and older adults' choices differ?}

Table 3 reports the log odds of choosing the option with the higher expected value ( $H$ choices) and the option with 


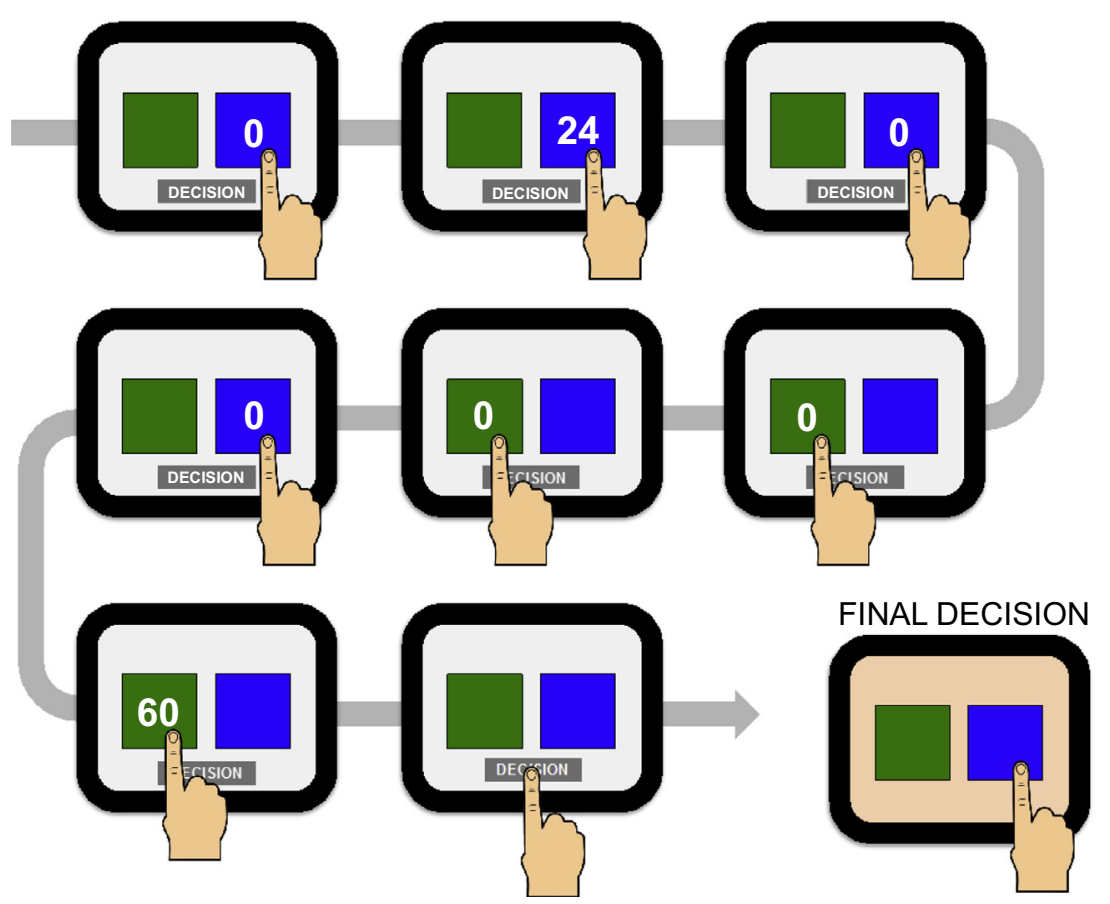

Fig. 1. Schematic representation of the sampling paradigm as used in Studies 1-3. During the first stage, participants can sample from the payoff distributions (green and blue boxes) without any consequences for their payoff. Only after pressing a "decision button" do participants indicate their final and consequential decision. (For interpretation of the references to colour in this figure legend, the reader is referred to the web version of this article.)

Table 2

Decision problems used in Study 1.

\begin{tabular}{|c|c|c|c|c|c|c|c|c|c|c|c|c|}
\hline \multirow[t]{2}{*}{ DP } & \multicolumn{2}{|l|}{ Options } & \multicolumn{2}{|c|}{ Expected value } & \multicolumn{2}{|c|}{ Sample size } & \multicolumn{2}{|c|}{$\begin{array}{l}\text { \% Observing } \\
\text { rare event }\end{array}$} & \multicolumn{2}{|c|}{ \% Choosing $H$} & \multicolumn{2}{|c|}{$\begin{array}{l}\text { \% Choosing } \\
H_{\text {exp }}\end{array}$} \\
\hline & $H$ & $L$ & $H$ & $L$ & Y. & O. & Y. & O. & Y. & O. & Y. & O. \\
\hline 1 & $4, .8$ & 3,1 & 3.2 & 3 & 26 & 22 & 87 & 84 & 46 & 58 & 61 & 69 \\
\hline 2 & $-3,1$ & $-4, .8$ & -3 & -3.2 & 36 & 25 & 87 & 70 & 59 & 72 & 67 & 81 \\
\hline 3 & $4, .2$ & $3, .25$ & .8 & .75 & 34 & 35 & 92 & 79 & 50 & 47 & 80 & 76 \\
\hline 4 & $-3, .25$ & $-4, .2$ & -.75 & -0.8 & 28 & 31 & 85 & 75 & 72 & 58 & 74 & 68 \\
\hline 5 & $32, .1$ & 3,1 & 3.2 & 3 & 30 & 25 & 73 & 51 & 23 & 33 & 57 & 79 \\
\hline 6 & $-3,1$ & $-32, .1$ & -3 & -3.2 & 31 & 28 & 75 & 62 & 73 & 63 & 92 & 90 \\
\hline 7 & $32, .025$ & $3, .25$ & .8 & .75 & 41 & 25 & 45 & 20 & 32 & 25 & 84 & 79 \\
\hline 8 & $-3, .25$ & $-32, .025$ & -.75 & -0.8 & 32 & 32 & 48 & 38 & 40 & 45 & 91 & 87 \\
\hline 9 & $6, .15$ & $.5, .75$ & .9 & .375 & 29 & 24 & 85 & 74 & 55 & 51 & 68 & 75 \\
\hline 10 & $-.5, .75$ & $-6, .15$ & -.375 & -.9 & 25 & 22 & 78 & 72 & 44 & 52 & 62 & 66 \\
\hline 11 & $13, .15$ & $.9, .7$ & 1.95 & .63 & 32 & 38 & 83 & 67 & 67 & 59 & 85 & 84 \\
\hline 12 & $-.9, .7$ & $-13, .15$ & -.63 & -1.95 & 25 & 26 & 80 & 69 & 47 & 56 & 63 & 79 \\
\hline
\end{tabular}

Note: $\mathrm{DP}=$ decision problem; $H=$ option with the higher expected value $(\mathrm{EV}) ; L=$ option with the lower EV. $H_{\text {exp }}=$ option with the higher experienced sample mean. $\mathrm{Y}=$ younger adults. $\mathrm{O}=$ older adults.

the higher experienced sample mean ( $H_{\exp }$ choices). As depicted in Fig. 2, younger and older adults chose the option with the higher expected value equally often, namely, in $51 \%$ and $52 \%$ of cases, respectively. The regression analysis suggests that there were no age effects, but a credible effect of domain (more $H$ choices in the domain of losses for both age groups). According to the Bayes factor analysis, it was 3.8 times more likely that there truly was no age difference in the proportion of $H$ choices than there was such a difference.

In sum, the proportions of higher expected value choices were around $50 \%$. So did younger and older adults choose randomly between options? Our results suggest the opposite: As Fig. 2 shows, younger and older adults chose the option with the higher experienced sample mean in $74 \%$ and $77 \%$ of cases, respectively. That is, younger and older adults made similar choices to the extent that they tended to choose the option that-based on their experience-promised the higher mean payoff. These options, however, were not necessarily always those with the higher expected value: In samples of limited size, the sample mean may deviate from the expected value and, in theory, only infinitely large samples will perfectly match the options' objective expected value ("law of large numbers"). 
Table 3

Fixed effects from multilevel modeling of younger and older adults' search and choice in Study 1.

\begin{tabular}{|c|c|c|c|c|c|c|c|c|c|}
\hline & \multicolumn{3}{|c|}{ Sample size } & \multicolumn{3}{|c|}{$H$ choices } & \multicolumn{3}{|c|}{$H_{\text {exp }}$ choices } \\
\hline & $b$ & HDI-l & HDI-u & $b$ & HDI-l & HDI-u & $b$ & HDI-l & HDI-u \\
\hline Intercept & 31.95 & 25.73 & 37.72 & -0.23 & -0.59 & 0.13 & 1.27 & 0.91 & 1.64 \\
\hline Domain (loss) & -2.39 & -6.52 & 1.43 & 0.55 & 0.18 & 0.94 & 0.13 & -0.31 & 0.57 \\
\hline Age group (older) & $-3.74^{\mathrm{a}}$ & -12.14 & 4.91 & 0 & -0.51 & 0.52 & 0.33 & -0.19 & 0.85 \\
\hline Domain $\times$ age group & 1.61 & -4.08 & 7.03 & 0.09 & -0.45 & 0.64 & -0.06 & -0.69 & 0.58 \\
\hline
\end{tabular}

Note: $H$ choices are choices favoring the option with the higher expected value. $H_{\text {exp }}$ choices are choices favoring the option with the higher experienced sample mean. HDI-l and HDI-u are the lower and upper 95\% highest density intervals. Sample size is predicted by generalized linear regression models. $H$ choices and $H_{\text {exp }}$ choices are predicted by logit regression models, that is, the coefficients are log odds. For example, the log odds of -.23 (the intercept for $H$ choices) translate into a probability of .44 of choosing the option with the higher expected value. Beta weights with highest density intervals that do not include 0 are printed in bold (except for the intercepts).

a When using a Poisson link function, the negative effect of age group on sample size, though small, is credible.
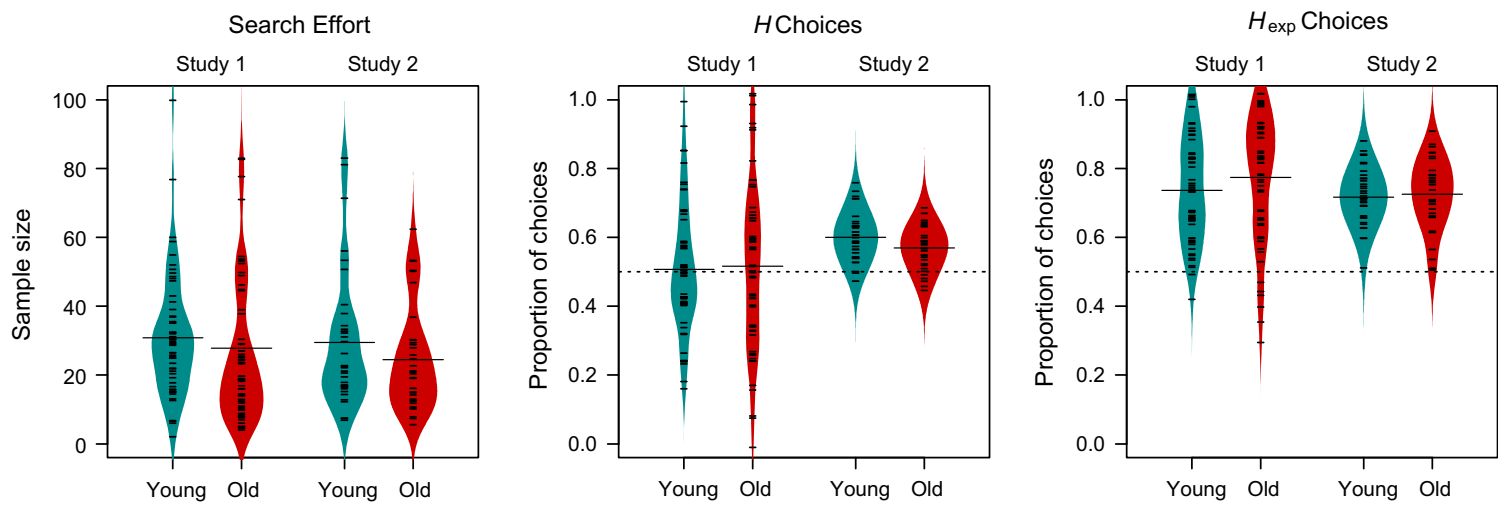

Fig. 2. Studies 1 and 2: Sample size and proportion of choices favoring the option with the higher expected value ( $H$ choices) and the option with the higher experienced sample mean $\left(H_{\text {exp }}\right.$ choices), separately for younger and older adults. The short horizontal lines indicate the mean choice proportions of each participant (jitter of .02 added); the long horizontal lines indicate the medians thereof.

\section{Study 2: Why are younger and older adults' decisions from experience in the sampling paradigm similar?}

Based on their findings on younger and older adults' decision making, Kovalchik et al. (2005) concluded that "the performance of the two groups of subjects is remarkably similar" (p. 89). The results of Study 1 suggest the same conclusion. Younger and older adults took samples of about equal size, with modest evidence that older adults may search slightly less. Consequently, the input into the choice process did not differ substantially as a function of age, nor did the output; that is, people's actual choices. Should one conclude that younger and older adults do not differ in decisions from experience?

The observed similarities do not rule out the possibility that younger and older adults arrive at similar choices on the basis of qualitatively different cognitive strategies. For example, although the older adults drew samples of about the same size as the younger adults, they may have eased the cognitive load by focusing their attention on the most recently sampled outcomes (recency effect). The smaller this subset of recent information, the more likely it is that rare but consequential events will be underrepresented (see Hertwig et al., 2004). Older adults may thus perceive such options to be much less risky than they in fact are. In contrast, younger adults may correctly perceive the same options to involve more risk. If younger adults are, in addition, more willing to take risks than older adults, both may ultimately prefer the same options-but for quite different reasons. To investigate the cognitive processes underlying decisions from experience, and to investigate which of these processes may vary as a function of age, we adopted a cognitive modeling approach in Study 2 .

\subsection{Cognitive models of decisions from experience}

There exist two different classes of models that describe how people make decisions from experience. First, neo-Bernoullian models assume that at the end of the sampling stage, people will have an accurate representation of all sampled outcomes and the probabilities with which these outcomes occurred in the sample. Based on the experienced information, people would then decide as if they processed the sampled outcomes and their associated probabilities similarly to how they make decisions from description. This class of models permits us to investigate whether younger and older adults' decisions suggest differences in risk preferences while taking into account the information each participant has actually experienced. That is, we can investigate to what extent younger and older adults weight the experienced probabilities in the 
same or in different ways. Second, learning models assume that choices result from an ongoing updating process, which forgoes the explicit representation of the sampled outcomes' probabilities of occurrence. Models within this class make different assumptions about how this updating process unfolds. They thus permit us to investigate whether younger and older adults rely on the same or different learning strategies (e.g., easing the cognitive load by focusing on more recently observed outcomes).

To illustrate these two classes, let us consider a trial in the sampling paradigm in which a person samples 12 times from two options $A$ and $B$ and experiences the following outcomes: $(7,0,0,7,13,7,13,0,0,0,7,0)$ from $A$ and $(0,0,1,0,0,18,1,0,18,0,18,18)$ from $B$. What are the models' assumptions about how a person determines which of the two options is more attractive?

\subsubsection{Neo-Bernoullian models}

The core assumption of this class of models is that decisions can or should be modeled in terms of Bernoulli's (1738/1954) theory of choice, which has become known as expected utility theory: People (and other animals) behave as if they multiply some function of probability and value, and then maximize. The most influential descriptive theory in this neo-Bernoullian tradition is cumulative prospect theory (CPT; Tversky \& Kahneman, 1992). It assumes a probability weighting function and a value function (see Appendix for details). When applied to the outcome sequences $A$ and $B$, a two-stage version of CPT (Fox \& Hadar, 2006) implies that a person chooses as if she (i) estimates the experienced probabilities of all unique outcomes in urn $A(0,7,13)$ and urn $B(0,1,18)$; (ii) enters the probabilities into a probability weighting and the outcomes into a value function; (iii) multiplies the resulting decision weights and subjective values; (iv) sums across all decision weight $\times$ value products, separately for each option; and ( $v$ ) maximizes. According to the neo-Bernoullian framework, probabilities are an indispensable building block of choice.

The two-stage version of CPT is mute as to how a person assesses the probabilities with which the sampled outcomes occurred. That is, a weakness of this model is that it does not describe the actual learning process. Nevertheless, on a purely descriptive level, the model may be informative for comparing whether probabilities of different magnitudes (e.g., rare events) have a similar impact on younger and older adults' decisions. Specifically, the probability weighting function has been hypothesized to vary between the two age groups (cf. Mata \& Hertwig, 2011; Peters, Hess, Västfjäll, \& Auman, 2007). To test this hypothesis, we implemented several versions of CPT (see Appendix for full specifications) with different probability weighting functions, and then used the version that best described participants' decisions to finally compare the estimated parameters between the two age groups.

\subsubsection{Learning and updating models}

The second class of models forgoes an explicit representation of the outcomes' probabilities and, by extension, the multiplication of probabilities (or decision weights) and outcomes (subjective values). Learning models (see e.g., Busemeyer \& Myung, 1992; Bush \& Mosteller, 1955; Estes, 1950; March, 1996) interpret choice-in the context of sequences of outcomes (see above)-as the result of accumulated learning. For example, a simple reinforcement-learning model (Sutton \& Barto, 1998) assumes that choices are based on expectancies that are updated from trial to trial; that is, from draw to draw in decisions from experience. Specifically, an expectation of an option's payoff is updated by adding a prediction error to the previous expectation, weighted by an individual learning rate. The prediction error is the difference between the old expectation of an option's payoff and the most recently experienced outcome (see Appendix for a full specification of this reinforcement-learning model).

One instantiation of such an ongoing updating process has been tested in the context of decisions from experience (albeit on the aggregate level). The value-updating model (VUM; Hau, Pleskac, Kiefer, \& Hertwig, 2008; Hertwig et al., 2004; Hogarth \& Einhorn, 1992) implies that a person chooses between the outcome sequences $A$ and $B$ as if she (i) calculates after each newly experienced outcome from a given option the average of the previously estimated value and the value of the most recently experienced outcome (see Appendix for details), and (ii) chooses the option with the highest value once all values in the sequences have been accumulated. In other words, the VUM estimates the mean reward promised by each option (weighted by a recency factor) and chooses the one with the higher mean reward, even if it carries more risk (e.g., in terms of outcome variance). We implement a series of learning models that differ in their assumptions about the specific updating process (see Appendix for the full specifications).

One of these learning models, the instance-based learning model (IBLM; Gonzalez \& Dutt, 2011), deserves particular attention because it makes detailed assumptions about specific cognitive processes, such as forgetting and memory retrieval. It builds on the ACT-R cognitive architecture (Anderson \& Lebiere, 1998, 2003) and its assumptions regarding the role of frequency and recency in human memory. The IBLM implies that a person faced with outcome sequences $A$ and $B$ (i) updates the activation of experienced outcomes (i.e., the instances) during the sampling process. In order to make a choice at the end of the sampling process, she (ii) retrieves the instances associated with an option from memory. The probability of retrieving instances from memory is, in turn, a function of their activation, and activation is a function of the instances' recency and frequency of observation. The person then (iii) determines the blended value of each option based on the probability of retrieving the associated instances and their corresponding outcomes, and finally (iv) chooses the option with the higher blended value. Previous investigations have shown that the IBLM can successfully describe decisions from experience on the aggregate level (Erev et al., 2010; Gonzalez \& Dutt, 2011). It remains to be tested, however, whether the IBLM also performs well in describing individual participants' decisions from experience, and to what extent the estimated parameters can capture individual differences in terms of cognitive abilities. 


\subsubsection{Overview of modeling aims}

The two classes of models describe either decision or learning processes on two fundamentally different levels. We will thus (a) identify the best model within each of these two classes and then (b) compare the estimated model parameters of the two classes' best performing model between the two age groups, and finally (c) relate the estimated parameters of these two models to individuals' cognitive abilities (the latter analyses are reported in Table A1 in the Appendix). To achieve these goals, we aimed to model decisions from experience on the level of individual participants, thus requiring a large number of decision problems per person. However, investigations of decisions from experience are time consuming (mainly due to the search component): Study 1 with 12 problems lasted, on average, $1 \mathrm{~h}$. In Study 2, we therefore presented decision problems via portable devices over the course of a week. Participants completed three daily sessions of four decision problems; we were thus able to record a total of 84 decisions per participant. To our knowledge, this is the most extensive investigation to date of single individuals' decisions from experience. Drawing on this large data set, we were able to test the models using individual data as compared to using aggregate data, which has commonly been done in the past (e.g., Erev et al., 2010; Gonzalez \& Dutt, 2011; Hau et al., 2008; Hertwig, Barron, Weber, \& Erev, 2006).

\subsection{Method}

\subsubsection{Participants}

We recruited two groups of participants from the subject pool database of the Department of Psychology at the University of Basel: 35 younger adults (30 female) aged 20 to 29 years $(M=23.0, S D=2.6)$ and 35 older adults (25 female) aged 63 to 82 years $(M=70.5, \quad S D=5.1)$. Participants received a fixed fee of $20 \mathrm{CHF}$ (approx. 21.9 USD) plus a performance-contingent bonus based on their choices across all sessions. Table 4 reports participants' sociodemographic characteristics.

\subsubsection{Procedure and measures of cognitive abilities}

Participants were invited to the laboratory for an introductory session, during which we collected demographic information and implemented the same measures of cognitive abilities as used in Study 1. Participants received written and oral instructions, explaining the purpose of the study, the monetary payoffs, and the operation of the portable device (iPad; see Fig. 1). After extensive practice with handling the iPad (see below), participants took the device home. On seven consecutive days, they completed a morning, afternoon, and evening session, each comprising four decision problems. They were free to choose the times of the sessions as long as there was at least a 3-h gap between them. The experimental program implemented the 3-h gap rule and ensured that no more than three sessions could be completed per day.

Both the practice session in the laboratory and each testing session at home started with participants rating their current emotional state and associated measures (reported in Table A2 in the Appendix). We collected these measures to assess and control for potential effects of
Table 4

Mean (SD) participant characteristics and statistics for the effects of age group in Study 2.

\begin{tabular}{|c|c|c|c|c|c|}
\hline \multirow[t]{2}{*}{ Characteristic } & \multicolumn{2}{|c|}{ Age group } & \multicolumn{3}{|c|}{ Statistic } \\
\hline & Young & Old & $\Delta$ & 95\% HDI & $d$ \\
\hline$N$ & 35 & 35 & & & \\
\hline Sex (female) & $\begin{array}{l}30 \\
(86 \%)\end{array}$ & $\begin{array}{l}25 \\
(71 \%)\end{array}$ & & & \\
\hline Age & $\begin{array}{l}23.0 \\
(2.6)\end{array}$ & $\begin{array}{l}70.5 \\
(5.1)\end{array}$ & & & \\
\hline Fluid abilities & $\begin{array}{l}64.7 \\
(8.6)\end{array}$ & $\begin{array}{l}45.5 \\
(9.7)\end{array}$ & -19.2 & $\begin{array}{l}-23.9 \text { to } \\
-14.8\end{array}$ & 2.13 \\
\hline $\begin{array}{c}\text { Crystallized } \\
\text { abilities }\end{array}$ & $\begin{array}{l}29.2 \\
(3.2)\end{array}$ & $\begin{array}{l}33.1 \\
(2.5)\end{array}$ & 3.9 & 2.4 to 5.3 & 1.35 \\
\hline Numeracy & $\begin{array}{l}8.8 \\
(1.5)\end{array}$ & $\begin{array}{l}7.8 \\
(2.2)\end{array}$ & -1 & -2.0 to -.1 & .55 \\
\hline \multicolumn{6}{|l|}{ Education } \\
\hline $\begin{array}{c}\text { Elementary } \\
\text { school }\end{array}$ & $5(14 \%)$ & $\begin{array}{l}20 \\
(57 \%)\end{array}$ & & & \\
\hline High school & $\begin{array}{l}23 \\
(66 \%)\end{array}$ & $1(3 \%)$ & & & \\
\hline University & 7 (20\%) & $\begin{array}{l}14 \\
(40 \%)\end{array}$ & & & \\
\hline \multicolumn{6}{|l|}{ Assets } \\
\hline$<40,000 \mathrm{CHF}$ & $\begin{array}{l}32 \\
(91 \%)\end{array}$ & $8(23 \%)$ & & & \\
\hline $\begin{array}{l}40,000-80,000 \\
\text { CHF }\end{array}$ & $2(6 \%)$ & 0 & & & \\
\hline$>80,000 \mathrm{CHF}$ & $1(3 \%)$ & $\begin{array}{l}27 \\
(77 \%)\end{array}$ & & & \\
\hline \multicolumn{6}{|l|}{ Debts } \\
\hline None & $\begin{array}{l}27 \\
(77 \%)\end{array}$ & $\begin{array}{l}24 \\
(73 \%)\end{array}$ & & & \\
\hline$<40,000 \mathrm{CHF}$ & $8(23 \%)$ & $3(9 \%)$ & & & \\
\hline$>40,000 \mathrm{CHF}$ & 0 & $6(18 \%)$ & & & \\
\hline
\end{tabular}

Note: Fluid abilities: digit-symbol substitution test (score range 0-93; Wechsler, 1981); crystallized abilities: spot-a-word (score range 0-37; Lehrl, 1977); numeracy scale (score range 0-10; Lipkus et al., 2001).

affect (see Frey, Hertwig, \& Rieskamp, 2014) and affect variability; both may differ between younger and older adults (Röcke, Li, \& Smith, 2009). During the practice session, participants completed six decisions problems (taken from Hertwig et al. (2004)) under the supervision of the experimenter. They were encouraged to ask questions about the device and the experimental procedure. In each of the 21 test sessions, four decision problems were presented (resulting in a total of 84 decisions). At the end of each session, participants received feedback on their total gain or loss in that session. This was done to raise awareness that each decision affected final payoffs. At the end of the seven days, participants returned to the laboratory to report any problems they had encountered and to receive their compensation. Throughout the course of the study, a research assistant was available by telephone to answer questions. Participants' final reports indicated that both younger and older adults found the handling of the portable device easy and intuitive.

\subsubsection{Decision problems}

All decision problems involved two options, each of which was associated with three different outcomes. We 
implemented three outcomes per option because this allowed us to control whether or not the magnitude of the expected outcomes was correlated with the degree of risk (see below). For each option, we first randomly defined a non-rare event that occurred with a probability $p_{1}$, ranging from .2 to .8 , and with an outcome $o_{1}$, ranging from 0 to $12 \mathrm{CHF}$ (in the following, all outcomes are given in Swiss francs; $1 \mathrm{CHF}=1.1 \mathrm{USD}$ ). We then randomly defined an event that occurred with a probability $p_{2}$, ranging from 0 to $.8-p_{1}$, and with an outcome $o_{2}$, ranging from 0 to 100. Finally, we generated a third event that occurred with a probability $p_{3}$, defined as $1-p_{1}-p_{2}$, and with an outcome $o_{3}$, ranging from 0 to 100 . The latter two could thus constitute rare events occurring with probabilities $<.2$ (as defined by Hertwig et al. (2004)).

From the resulting set of options, we selected two sets. The low expected value (EV) set comprised options whose EVs ranged from 4.8 to 5.2 ; the high EV set comprised options whose EVs ranged from 5.8 to 6.2. From each of these sets, we sampled two subsets, one containing options whose variance ranged from 10 to 30 and one containing options whose variance ranged from 60 to 80 . This resulted in four sets of options: (1) One including options with a high EV and a high variance $(\mathrm{HH}) ;(2)$ one including options with a high EV and a low variance $(\mathrm{HL})$; (3) one including options with a low EV and a high variance (LH), and (4) one including options with a low EV and a low variance (LL). We constructed the decision problems on the basis of these four sets. Specifically, we randomly paired either an $\mathrm{HH}$ (high EV but relatively risky) option with an LL (low EV but relatively safe) option, or an HL (high EV and relatively safe) option with an LH (low EV and relatively risky) option. We then reflected these sets to obtain the respective decision problems in the loss domain.

We randomly generated a single order of decision problems such that all participants were presented with the same four problems in each session: Two gain and two loss problems, with one problem having an option with a high EV and a high variance and the other having a high EV and a low variance.

\subsection{Results}

As in Study 1, we first analyzed search and choice independently of each other; we then linked the two through computational modeling. We again considered the effects of age group and domain (gain/loss), as well as their interaction. In addition, we considered problem difficulty: In easy problems, one option dominated the other in terms of higher expected value and lower variance (i.e., an HL and an LH option, see above). In hard problems, one option dominated the other in terms of higher expected value, but also had a higher variance (i.e., an $\mathrm{HH}$ and an LL option).

\subsubsection{Did younger and older adults' search effort differ?}

Table 5 presents the results of the mixed-effects general linear model that was used to analyze search. First and foremost, search effort as gauged with the portable devices was very similar to that observed in Study 1 (Fig. 2). On average, younger adults sampled 30 times in the gain domain and 29 times in the loss domain; older adults sampled 25 times in the gain domain and 24 times in the loss domain. Thus, as in Study 1, older adults tended to take smaller samples than younger adults. Even though this was not a credible difference according to the 95\% HDI, the Bayes factor analysis suggested that it was 8.7 times more likely that there truly was an age difference in search effort than there was no such difference. Search effort, however, did not differ as a function of gain/loss domain, difficulty, or the interactions (Table 5).

Older adults' slightly smaller sample sizes showed a tendency to impact their experience of rare events (i.e., events occurring with a probability <.2; Hertwig et al., 2004). Specifically, younger adults experienced the rare events involved in a decision problem at least once in $28 \%$ of the decision problems, and older adults in $25 \%$ of the decision problems. According to a Bayesian $t$ test (Kruschke, 2013), the mean difference of 3\% (95\% HDI: 0.2 to $6.7 \%$ ) constituted a credible effect with an effect size of .51 .

Our repeated-measurement design also allowed us to investigate the possibility that younger and older adults differed in how consistently they sampled. We calculated the within-person standard deviation of sample sizes across sessions, and compared these standard deviations between age groups. Both younger and older adults were equally consistent in search, with mean standard deviations of $12.6(S D=7.0)$ and $12.6(S D=11.2)$, respectively.

\subsubsection{Did younger and older adults' choices differ?}

Table 5 reports the log odds of choosing the option with the higher expected value ( $H$ choices) and the option with

Table 5

Fixed effects from multilevel modeling of younger and older adults' search and choice in Study 2.

\begin{tabular}{|c|c|c|c|c|c|c|c|c|c|}
\hline & \multicolumn{3}{|c|}{ Sample size } & \multicolumn{3}{|c|}{$H$ choices } & \multicolumn{3}{|c|}{$H_{\text {exp }}$ choices } \\
\hline & $b$ & HDI-l & HDI-u & $b$ & HDI-l & HDI-u & $b$ & HDI-l & HDI-u \\
\hline Intercept & 29.42 & 23.75 & 35.77 & 0.57 & 0.36 & 0.79 & 1.28 & 1.02 & 1.54 \\
\hline Domain (loss) & -0.6 & -1.83 & 0.63 & 0.1 & -0.1 & 0.3 & -0.02 & -0.24 & 0.21 \\
\hline Age group (older) & -4.99 & -13.48 & 3.2 & -0.07 & -0.38 & 0.23 & 0.01 & -0.36 & 0.38 \\
\hline Difficulty (hard) & 0.69 & -0.44 & 1.9 & -0.24 & -0.48 & -0.01 & -0.22 & -0.43 & 0 \\
\hline Domain $\times$ age group & 0.3 & -1.37 & 1.97 & -0.2 & -0.48 & 0.07 & -0.1 & -0.43 & 0.23 \\
\hline Age group $\times$ difficulty & -0.27 & -1.9 & 1.37 & 0.04 & -0.3 & 0.37 & 0.2 & -0.11 & 0.51 \\
\hline
\end{tabular}

Note: $H$ choices are choices favoring the option with the higher expected value. $H_{\text {exp }}$ choices are choices favoring the option with the higher experienced sample mean. HDI-l and HDI-u are the lower and upper 95\% highest density intervals. Sample size is predicted by generalized linear regression models. $H$ choices and $H_{\text {exp }}$ choices are predicted by logit regression models, that is, the coefficients are log odds. For example, the log odds of .57 (the intercept for $H$ choices) translate into a probability of .64 of choosing the option with the higher expected value. Beta weights with highest density intervals that do not include 0 are printed in bold (except for the intercepts). 
the higher experienced sample mean ( $H_{\exp }$ choices). As depicted in Fig. 2, younger and older adults chose the option with the higher expected value in $60 \%$ and $57 \%$ of cases, respectively. The regression analysis suggests that there were no effects of age or of domain (Table 5). However, in easy problems, younger and older adults chose the option with the higher expected value credibly more often (in $62 \%$ and $59 \%$ of cases, respectively) than they did in hard problems (in 58\% and 55\% of cases, respectively). Fig. 2 also shows that younger and older adults chose the option with the higher experienced sample mean in a similar proportion of cases, namely, in $72 \%$ and $73 \%$ of cases. There were no effects of age, domain, or problem difficulty (Table 5). According to the Bayes factor analysis, it was 5.7 (5.4) times more likely that there truly was no age difference in the proportion of $H$ choices $\left(H_{\text {exp }}\right.$ choices) than there was such a difference.

\subsubsection{Cognitive modeling}

We fitted the different models (described in detail in the Appendix) to individual participants' search and choice data. All models were fitted with an exponential choice rule, once with a free choice sensitivity parameter and once with the choice sensitivity parameter fixed to 1 (see Appendix). The choice sensitivity parameter did not influence the estimated model parameters systematically; therefore, we report only results from the model versions with a free choice sensitivity parameter (note that we also implemented the IBLM using a probabilistic choice rule; see Appendix for details).

The first analysis focused on CPT and whether there were differences between younger and older adults' probability weighting (i.e., differences in risk-taking preferences). To this end, we first determined which of the implemented CPT versions performed best in describing participants' decisions (in terms of Bayesian model weights; Lewandowsky \& Farrell, 2010). As can be seen in Fig. 3 (upper panels), there was "positive" to "very strong" evidence (Raftery, 1995) that at least one of the implemented versions of CPT was able to describe most participants' decisions better than a baseline model assuming random choice (specifically, of 31 of the 35 younger and 30 of the 35 older adults). In both age groups, a version of CPT with only one free parameter in the probability weighting function ("PR1," see Appendix) was best able to describe participants' decisions. Fig. 3 shows the value functions and probability weighting functions resulting from the estimated model parameters. Each curve represents one individual, and the thick curves represent the aggregated parameters (i.e., the modes of the posterior distributions of each age group). As can be seen, the aggregated parameter values (Table 6) resulted in relatively similar CPT functions (Bayesian $t$ tests indicated that none of the parameters differed credibly between age groups), with a trend for younger adults to "underweight rare events" whereas older adults weighting functions were relatively linear. However, older adults' choice sensitivity parameters tended to be slightly (but not credibly) lower than those of younger adults.

Next, we determined which of the learning models performed best in describing participants' choices, and whether the estimated parameters suggested any differences in younger and older adults' learning processes. Fig. 4 shows the participant classification to the different learning models according to Bayesian model weights (Lewandowsky \& Farrell, 2010). In both age groups, the delta-rule learning model (see Appendix) was best able to describe most of the younger and older adults' decisions. Thus, at large, there were no substantial qualitative differences in younger and older adults' learning processes. However, whereas the delta-rule learning model was clearly the best performing model in younger adults, notable proportions of older adults were best described by one of the other learning models (though not by the two versions of the IBLM). A possible explanation for some of the older adults shifting to other learning strategies, such as the VUM, may be that the respective cognitive processes are less taxing. Surprisingly, the two versions of the IBLM performed poorly in both age groups, suggesting that this model makes too specific assumptions to adequately describe individual (relative to aggregate) learning processes.

All of the implemented learning models involve a learning parameter (modeling either recency or memory decay, which can be considered the inverse of recency) as well as a choice sensitivity parameter. Table 6 shows that there were only small differences in these parameters between the two age groups (Table 6), suggesting that there were no quantitative differences in younger and older adults' learning processes. Bayesian $t$ tests further revealed no credible differences between younger and older adults' choice sensitivities.

\subsubsection{Discussion}

Results of Study 1 suggested that younger and older adults' information search and choices in the sampling paradigm are relatively similar. Although using a different tool to record decisions from experience (mobile devices vs. lab computers), and many more decision problems (84 vs. 12) that involved three as compared to two outcomes per decision option, Study 2 also found similar search and choice behaviors across age groups. Younger and older adults did not differ credibly in search effort, proportion of higher expected value choices, and higher experienced sample mean choices. Moreover, both younger and older adults' search and choices showed little susceptibility to gain/loss framing.

The modeling analysis suggests that this behavioral similarity also extends to similarity on the level of the modeled cognitive processes. In two classes of models we found only small differences between younger and older adults in terms of the best performing models as well as in terms of the estimated model parameters. The aggregated parameters estimated by CPT suggest that younger adults tend to make choices as if small probability events have less impact than they deserve ("underweighting" of rare events); the decisions made by older adults implied fairly linear probability weighting. The two age groups, however, did not differ credibly with respect to these CPT parameters. Overall, CPT achieved a better fit than the learning models (Table 6). CPT's relatively good fit may partly result from its requirement that the precise 
Younger Adults
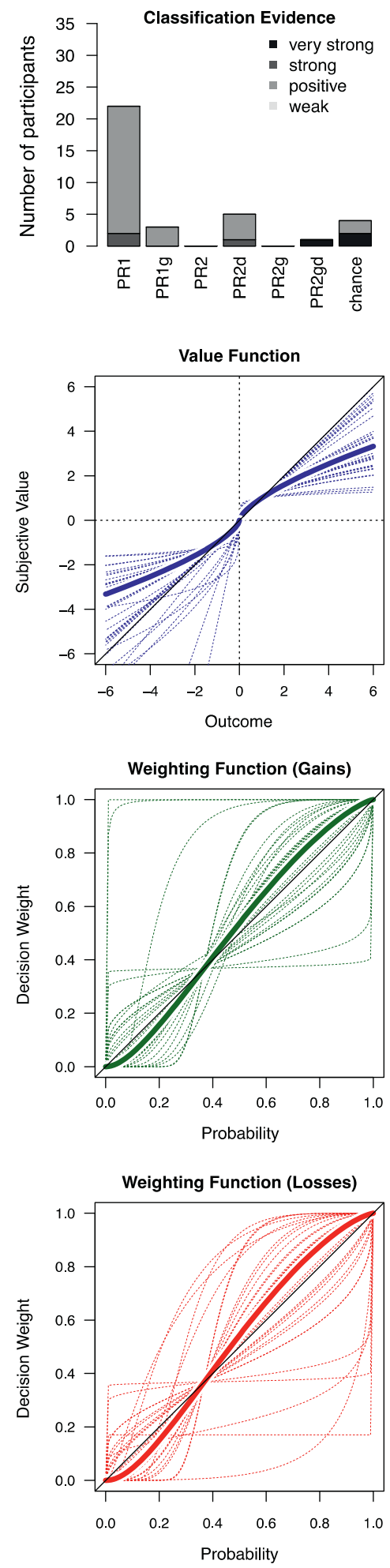

Older Adults
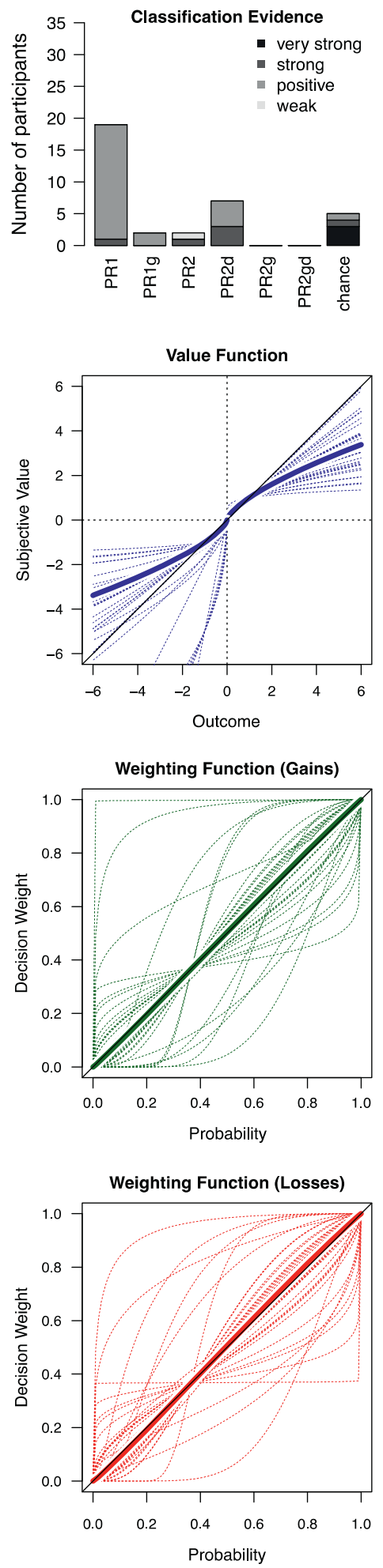

Fig. 3. Study 2: Participant classification (according to Bayesian model weights) and resulting value functions and probability weighting functions, separately for younger adults (left panels) and older adults (right panels). For plotting the aggregate curves, the modes of the posterior distribution of the respective parameters were used. 


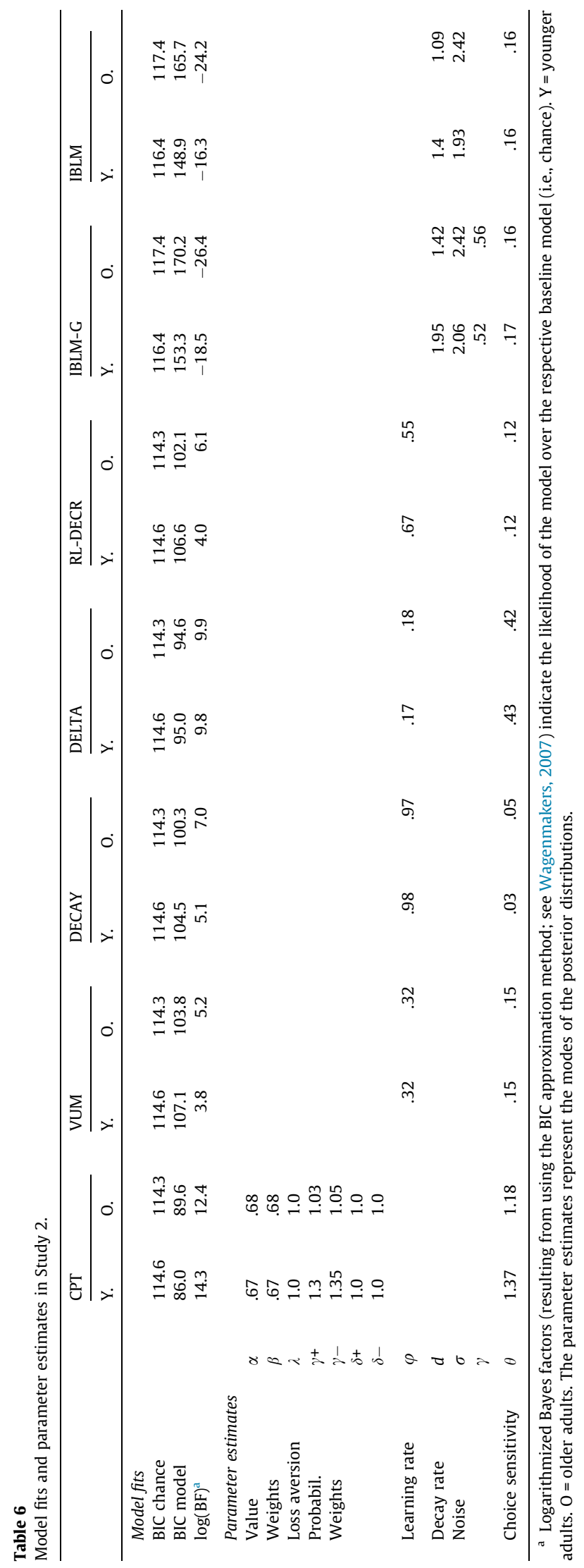




\section{Younger Adults}

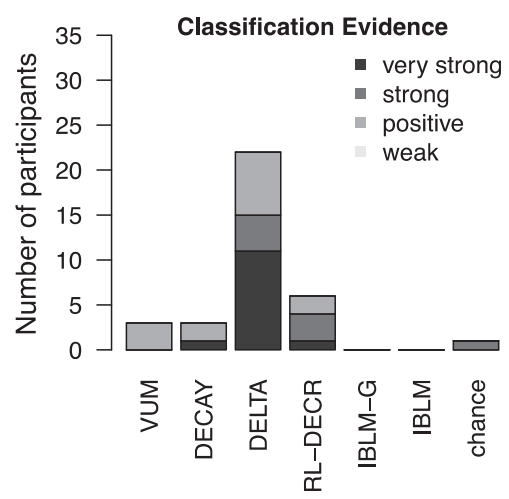

Older Adults

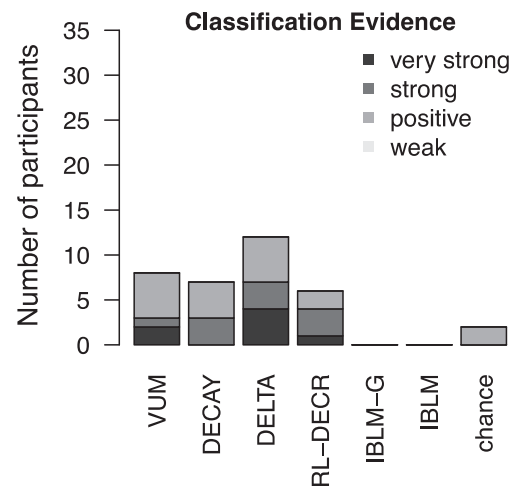

Fig. 4. Study 2: Participant classification (according to Bayesian model weights) to six different learning models and a baseline chance model.

probabilities (i.e., the probabilities with which an individual experienced the various outcomes during sampling) are supplied to the model. The learning models, in contrast, have the additional challenge of making sense of the raw sampling data to capture the actual learning process. Several learning models were successful in describing participants' choices, in particular the delta-rule learning model. Thus, one possible interpretation of our results showing no age differences in the sampling paradigm is that the updating process of an option's value is automatic and does not substantially rely on those fluid cognitive abilities that decline with aging (Hasher \& Zacks, 1984).

In sum, the computational modeling in Study 2 suggests a reason why age differences do not become manifest in the sampling paradigm: Both younger and older adults used similar learning and decision strategies that were well adapted to the task (for a similar finding, see Queen, Hess, Ennis, Dowd, \& Grühn, 2012). Yet, it is conceivable that by increasing the informational and computational demands posed by the choice environment, age differences in decisions from experience may emerge. We next turn to such demands.

\section{Study 3: When do younger and older adults' decisions from experience diverge?}

In Studies 1 and 2, younger and older adults made similar decisions from experience, despite substantial differences in cognitive abilities. The modeling results suggest that-in the sampling paradigm with only two options per decision problem and no exploration-exploitation trade off-both younger and older adults could successfully rely on simple learning processes. But how do younger and older adults perform when more than two options are to be explored? In order to address this question, we increased the complexity of the choice environment by implementing the sampling paradigm with two, four, and eight payoff distributions. Increasing the number of options makes the sampling paradigm more similar to other experience-based choice paradigms in which age differences have previously been observed, such as the Iowa Gambling Task (Bechara et al., 1994). However, as the learning phase still remains separate from the decision phase, we can investigate the extent to which learning difficulties per se explain potential age-related differences in decisions from experience.

\subsection{Method}

\subsubsection{Participants}

We recruited two groups of participants using the subject pool database of the Max Planck Institute for Human Development, Berlin. The group of younger adults included 41 individuals (16 female), aged 19 to 34 years $(M=25.1$, $S D=3.7)$; the group of older adults included 43 individuals (17 female), aged 66 to 82 years $(M=70.5, S D=3.6)$. Additional sociodemographic characteristics are listed in Table 7. Participants received a fixed fee of 10 euro (EUR; approx. 13.7 USD) plus a performance-contingent bonus based on their choices.

\subsubsection{Procedure and decision problems}

Participants were invited to a laboratory session. They were first familiarized with the sampling paradigm, including a practice trial, and were then informed that they would render 12 decisions from experience with different choice set sizes (consisting of two, four, and eight options, respectively). We varied the order of presentation of the different set sizes because previous research suggests that there are significant primacy effects, depending on whether the small (two options) or large set (eight options) is presented first (Hills, Noguchi, \& Gibbert, 2013). Specifically, we randomly assigned participants to one of two between-subjects conditions: "increasing" or "decreasing" order. In the former, participants first completed three decision problems with two options, followed by three decision problems with four options, and finally three decision problems with eight options. In the latter, this order was reversed. That is, we used a mixed design with the between-subjects factors "age group" (young vs. old) and "problem order" (increasing vs. decreasing) and a within-subjects factor "set size" (two vs. four vs. eight).

We constructed the decision problems in the following way: First, we selected all decision options (i.e., payoff 
Table 7

Mean (SD) participant characteristics and statistics for the effects of age group in Study 3.

\begin{tabular}{|c|c|c|c|c|c|}
\hline \multirow[t]{2}{*}{ Characteristic } & \multicolumn{2}{|c|}{ Age group } & \multicolumn{3}{|c|}{ Statistic } \\
\hline & Young & Old & $\Delta$ & 95\% HDI & $d$ \\
\hline$N$ & 41 & 43 & & & \\
\hline Sex (female) & $\begin{array}{l}16 \\
(39 \%)\end{array}$ & $\begin{array}{l}17 \\
(40 \%)\end{array}$ & & & \\
\hline Age & $\begin{array}{l}25.1 \\
(3.7)\end{array}$ & $\begin{array}{l}70.5 \\
(3.6)\end{array}$ & & & \\
\hline Fluid abilities & $\begin{array}{l}60.2 \\
(8.4)\end{array}$ & $\begin{array}{l}42.0 \\
(9.3)\end{array}$ & -18.2 & $\begin{array}{l}-22.1 \text { to } \\
-14.4\end{array}$ & 2.1 \\
\hline $\begin{array}{l}\text { Crystallized } \\
\text { abilities }\end{array}$ & $\begin{array}{l}31.2 \\
(2.5)\end{array}$ & $\begin{array}{l}33.1 \\
(2.0)\end{array}$ & 1.9 & 1.0 to 3.1 & .89 \\
\hline Numeracy & $\begin{array}{l}2.3 \\
(1.0)\end{array}$ & $\begin{array}{l}1.6 \\
(1.1)\end{array}$ & -0.7 & $\begin{array}{l}-1.84 \text { to } \\
-0.38\end{array}$ & .72 \\
\hline Operation span & $\begin{array}{l}.83 \\
(.12)\end{array}$ & $\begin{array}{l}.57 \\
(.20)\end{array}$ & -.26 & $\begin{array}{l}-.34 \text { to } \\
-.19\end{array}$ & 1.63 \\
\hline $\begin{array}{l}\text { Associative } \\
\text { recall }\end{array}$ & $\begin{array}{l}.54 \\
(.24)\end{array}$ & $\begin{array}{l}.20 \\
(.18)\end{array}$ & -.34 & $\begin{array}{l}-.44 \text { to } \\
-.25\end{array}$ & 1.61 \\
\hline \multicolumn{6}{|l|}{ Education } \\
\hline $\begin{array}{c}\text { Elementary } \\
\text { school }\end{array}$ & $4(10 \%)$ & $\begin{array}{l}21 \\
(49 \%)\end{array}$ & & & \\
\hline High school & $\begin{array}{l}26 \\
(63 \%)\end{array}$ & $4(9 \%)$ & & & \\
\hline University & $\begin{array}{l}11 \\
(27 \%)\end{array}$ & $\begin{array}{l}18 \\
(42 \%)\end{array}$ & & & \\
\hline \multicolumn{6}{|l|}{ Assets } \\
\hline$<40,000 \mathrm{CHF}$ & $\begin{array}{l}40 \\
(98 \%)\end{array}$ & $\begin{array}{l}16 \\
(37 \%)\end{array}$ & & & \\
\hline $\begin{array}{l}40,000-80,000 \\
\text { CHF }\end{array}$ & $1(2 \%)$ & $8(19 \%)$ & & & \\
\hline$>80,000 \mathrm{CHF}$ & 0 & $\begin{array}{l}19 \\
(44 \%)\end{array}$ & & & \\
\hline \multicolumn{6}{|l|}{ Debts } \\
\hline$<40,000 \mathrm{CHF}$ & $\begin{array}{l}41 \\
(100 \%)\end{array}$ & $\begin{array}{l}40 \\
(93 \%)\end{array}$ & & & \\
\hline $\begin{array}{l}40,000-80,000 \\
\text { CHF }\end{array}$ & 0 & 0 & & & \\
\hline$>80,000 \mathrm{CHF}$ & 0 & $3(7 \%)$ & & & \\
\hline
\end{tabular}

Note: Fluid abilities: digit-symbol substitution test (score range 0-93; Wechsler, 1981); crystallized abilities: spot-a-word (score range 0-37; Lehrl, 1977); numeracy scale (score range 0-3; Lipkus et al., 2001); operation span (score range $0-1$; Unsworth et al., 2005); associative recall (score range 0-1; Shing et al., 2008).

distributions) from Study 2 that (a) involved only gains, (b) included a rare event (i.e., an event with a probability of less than .2), and (c) had either a high expected value and high variance or a low expected value and low variance (i.e., expected value and risk were correlated-we thus avoided dominating decision options). From each of the two resulting sets of decision options (one set of options with high expected values; one set of options with low expected values), we randomly sampled either one, two, or four decision options, thus resulting in three decision problems with two, four, and eight decision options.

\subsubsection{Measures of cognitive abilities}

We used the same measures of cognitive abilities as in Studies 1 and 2. In addition, we implemented measures of working memory capacity (operation span test;
Unsworth, Heitz, Schrock, \& Engle, 2005) and episodic memory (associative recall task; Shing, Werkle-Bergner, Li, \& Lindenberger, 2008). Summary statistics for all measures are reported in Table 7. As in the previous studies, younger adults outperformed older adults in fluid abilities (digit-symbol substitution task) and numeracy, but not in crystallized abilities (vocabulary). In addition, the younger adults also outperformed the older adults in working memory capacity and episodic memory performance.

\subsection{Results}

We analyzed younger and older adults' decisions from experience on two levels, namely, search and choice. For search, we used a mixed-effects general linear model (random effects over participants) with sample size (search effort) as dependent variable, and age group (younger vs. older adults), set size (two vs. four vs. eight), and their interaction as fixed effects. We ran the analyses separately for the two conditions (increasing vs. decreasing) for ease of interpretability. For choice, we used logistic regression on the option with the higher expected value ( $H$ choices) and the option with the higher experienced sample mean ( $H_{\exp }$ choices), with the same predictors (age group, set size, and interaction).

\subsubsection{Did younger and older adults' search effort differ?}

Table 8 presents the fixed-effects coefficients estimated in the mixed-effects general linear model that was used to analyze search (i.e., sample size). In both conditions, participants sampled substantially more with a greater number of options per decision problem (Fig. 5). In the "decreasing" condition, there was a credible interaction between age group and number of decision options. Specifically, as to be expected based on the result of Studies 1 and 2, younger and older adults did not differ in search effort when each problem involved two options. Older adults, however, sampled substantially less than younger adults when there were more options per decision problem. In the "increasing" condition, in contrast, there was no such interaction, but a credible main effect for age group, indicating that older adults sampled less regardless of how many options there were in a decision problem. The order effect observed in our study is consistent with the one reported in Hills et al. (2013), where participants overall sampled more if they started with decision problems involving few options and moved on to decision problems involving more options ("few-to-many"), as compared to the other way round ("many-to-few"). Our results suggest that older adults are affected by this order effect much more strongly, relative to younger adults. In other words, they seem to suffer less from choice overload if they have the chance to start with few options and work toward the more complex decision problems, as compared to when they have to start with the complex decision problems right away.

\subsubsection{Did younger and older adults' choices differ?}

Table 8 reports the log odds of choosing an option with higher expected value ( $H$ choices; i.e., choosing the option with the higher EV in decision problems with 2 options, or 
Table 8

Fixed effects from multilevel modeling of younger and older adults' search and choice in Study 3.

\begin{tabular}{|c|c|c|c|c|c|c|c|c|c|}
\hline & \multicolumn{3}{|c|}{ Sample size } & \multicolumn{3}{|c|}{$H$ choices } & \multicolumn{3}{|c|}{$H_{\text {exp }}$ choices } \\
\hline & $b$ & HDI-l & HDI-u & $b$ & HDI-l & HDI-u & $b$ & HDI-l & HDI-u \\
\hline \multicolumn{10}{|l|}{ Condition: Increasing } \\
\hline Intercept & 15.08 & 6.64 & 23.45 & 0.33 & 0.19 & 0.48 & 0.7 & 0.54 & 0.85 \\
\hline Set size & 14.39 & 11.37 & 17.73 & 0.03 & 0 & 0.05 & -0.03 & -0.06 & 0 \\
\hline Age group (older) & -16.01 & -28 & -4.47 & 0.08 & -0.14 & 0.26 & -0.02 & -0.23 & 0.2 \\
\hline Set size $\times$ age group & -2.86 & -7.2 & 2.02 & -0.01 & -0.05 & 0.03 & -0.01 & -0.05 & 0.03 \\
\hline \multicolumn{10}{|l|}{ Condition: Decreasing } \\
\hline Intercept & 18 & 7.4 & 28.27 & 0.33 & 0.18 & 0.48 & 0.74 & 0.59 & 0.89 \\
\hline Set size & 9.71 & 6.76 & 12.25 & 0.03 & 0 & 0.06 & -0.04 & -0.07 & -0.02 \\
\hline Age group (older) & 6.64 & -8.65 & 20.19 & 0.13 & -0.08 & 0.33 & -0.21 & -0.42 & 0.01 \\
\hline Set size $\times$ age group & -7.46 & -11.05 & -3.46 & -0.01 & -0.05 & 0.03 & 0.03 & -0.01 & 0.06 \\
\hline
\end{tabular}

Note: $H$ choices are choices favoring one of the options with higher expected value. $H_{\text {exp }}$ choices are choices favoring the option with the highest experienced sample mean. HDI-l and HDI-u are the lower and upper $95 \%$ highest density intervals. Sample size is predicted by generalized linear regression models. $H$ choices and $H_{\text {exp }}$ choices are predicted by logit regression models, that is, the coefficients are log odds. For example, the log odds of .33 (the intercept for $H$ choices in the "increasing" condition) translate into a probability of .58 of choosing an option with higher expected value. Beta weights with highest density intervals that do not include 0 are printed in bold (except for the intercepts).

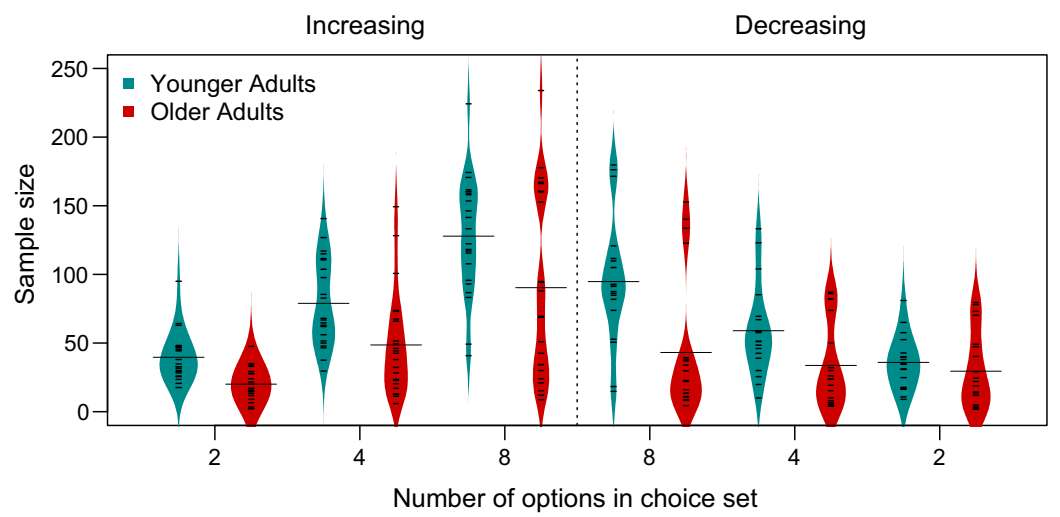

Fig. 5. Study 3: Sample size as a function of the different choice set sizes, separately for younger and older adults and the two conditions. The long horizontal lines represent medians.

choosing one of the 2 or 4 options with higher EV in decision problems with 4 and 8 options) and the option with the highest experienced sample mean ( $H_{\exp }$ choices). Both younger and older adults chose one of the higher expected value options in almost $60 \%$ of cases, and we did not observe any interactions with the number of decision options. Further, almost 70\% of younger and older adults' choices represented the option with the highest experienced sample mean. Here, we observed a credible main effect in the "decreasing" condition: Independent of the number of decision options, older adults chose the option with the higher experienced sample mean less often than the younger adults did.

\section{Do cognitive abilities correlate with search effort?}

Does cognitive ability underlie individual and age differences in decisions from experience? The pattern of findings from the three studies above suggests that cognitive abilities should not play a particularly important role in simple decision situations but may be more relevant in more complex situations, for example, involving many decision options. To assess this hypothesis, we calculated correlations between individuals' scores on the fluid abilities measure and their search effort in the three studies. We ran correlations separately for younger and older adults because mean age group differences in the individual difference measures are known to bias analyses across age groups (Hofer \& Sliwinski, 2001). As can be seen in Fig. 6, fluid abilities show negligible correlations with search effort in conditions involving decision between two options, rs $<|.1|$. However, the correlation between fluid abilities and search was larger in conditions involving more than two options, $r s>.2$, particularly for older adults. These results are in line with the idea that cognitive abilities can be a determinant of search effort in decisions from experience; however, only in conditions involving increased search requirements.

\section{General discussion}

Cognitive abilities decline with age (Li et al., 2004; Nilsson et al., 2004; Schaie, 2012). Yet, it is unclear to what extent cognitive aging is associated with declining levels of 


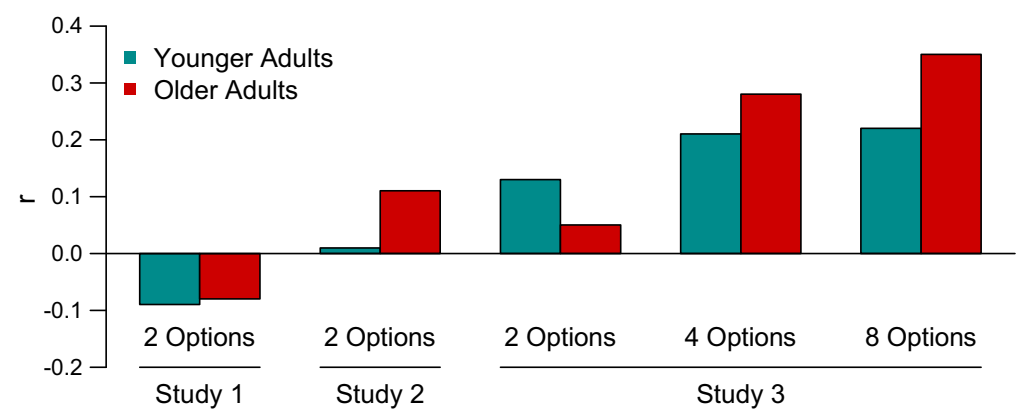

Fig. 6. Pearson's correlation coefficients between fluid abilities and search effort, separately for younger and older adults and the three studies. Studies 1 and 2 only involved decision problems with 2 decision options, whereas Study 3 involved decision options with 2, 4, and 8 decision options.

choice performance. The empirical results have been mixed, with some authors observing a profound decline in choice rationality (Agarwal, Driscoll, Gabaix, \& Laibson, 2009; Boyle, Yu, Buchman, Laibson, \& Bennett, 2011; Tymula et al., 2013) and others observing no decline relative to the decision-making performance of younger adults-or even improvement in specific tasks (Del Missier et al., 2013; Kovalchik et al., 2005; Li, Baldassi, Johnson, \& Weber, 2013). Our findings revealed both: Instances of decisions from experience that were not substantially impaired by cognitive aging, and others that were.

Using a popular sampling paradigm, we found the following regularities across three studies: In the commonly studied version of this paradigm (i.e., two decision options), older adults explored only slightly less than younger adults did. Moreover, younger and older adults' overall propensities to choose the higher expected value option (or, alternatively, the option with the higher experienced sample mean) were similar (across gain vs. loss domains and levels of choice difficulty). We thus found no marked age differences in decisions from experience with the standard version of the sampling paradigm. Our cognitive modeling analyses suggest a possible reason for these regularities: Younger and older adults seem to successfully rely on similar updating strategies, which may be relatively insensitive to the effects of cognitive aging. To the extent that ongoing updating processes (of frequencies of occurrences or of sample means) unfold relatively automatically and effortlessly (Hasher \& Zacks, 1984), older adults may be liberated from the detrimental consequences of cognitive aging in the case of decisions from experience with few decision options. These results are consistent with the thesis that updating processes may be relatively resistant to the effects of cognitive aging (Samanez-Larkin, Wagner, \& Knutson, 2011).

The results from Study 3, in contrast, suggest that age differences become evident as information load and, by extension, the demands on cognitive resources increase. Although younger and older adults potentially still rely on the same updating strategies (e.g., the simple delta-learning rule) with more than two options, they have to keep track of their current evaluations of multiple (up to eight) payoff distributions. Arguably, this task is cognitively much more taxing than the tracking of two options. Consequently, older adults may aim to reduce complexity and cognitive burden by decreasing search effort per option. These results underscore the importance of understanding the role of specific demands that are imposed by the choice environment when predicting patterns of decision performance as a function of age or cognitive abilities.

\subsection{Implications}

Our results are in line with the notion of ecological rationality, which suggests that specific strategies-even simple approximating ones-can perform well in some environments (Mata et al., 2012). Consequently, decision strategies that are less subject to normal cognitive aging and declines in cognitive abilities may enable older adults to make decisions that are as good as those made by younger adults, despite sizable effects of aging on intellectual functioning. Our results suggest that age differences in decision performance are not observed across the board, but rather vary as a function of the demands imposed by the task (Del Missier et al., 2013; Kovalchik et al., 2005; Li et al., 2013). Taken together, the results suggest that there is no general answer to the question of whether cognitive aging affects decision making. Rather, the impact of aging on decision making will-potentially dramaticallydiffer as a function of the demands of the ecology or task. The goal of future research must be to understand the match between the developmental path of the mind's core abilities, on the one hand, and the diverse demands of decision environments and specific tasks, on the other.

Our results also inform research on decisions from experience using the sampling paradigm (Hertwig \& Erev, 2009; Hertwig et al., 2004). In this paradigm, individual differences in fluid cognitive abilities (e.g., working memory) do not seem to be key determinants of interindividual differences in search and choice. Fluid intelligence has been discussed as a predictor of search in the context of decisions from experience (Rakow et al., 2008, 2010), but based on our results it appears that its impact is negligible in the choice ecologies typically implemented with the sampling paradigm. Finally, to the best of our knowledge, our study is the first to fit CPT parameters to a large set of decisions from experience on the level of individual participants. According to this analysis, the resulting CPT 
functions varied substantially from participant to participant, both within younger and older adults. However, younger adults weighting pattern tended to be in line with the one that has commonly been hypothesized from aggregate choice data, namely, that rare events have less impact on people's decisions than they deserve according to their objective probabilities (Barron \& Erev, 2003; Hertwig et al., 2004). This "underweighting" of rare events is opposite to the "overweighting" of rare events inferred from decisions from description (Tversky \& Kahneman, 1992). A number of analyses investigated the suggested differential probability weighting in experience- and description-based choice using different methods (for a review, see Hertwig, 2015). Clearly, the question of probability weighting in decisions from experience is not finally settled but our investigation offers an important contribution to this debate, based on the analysis of individual rather than aggregated data.

\subsection{Limitations and future research}

Our decision problems represent just some of the many existing ecologies of decisions from experience, and the role of cognitive abilities and potential age differences in other ecologies need to be tested. For example, age differences or lack thereof also need to be examined in the partial- and full-feedback paradigms (see Hertwig \& Erev, 2009). Similarly, it will be necessary to better understand the differences between the sampling paradigm and other experience-based paradigms, such as the Iowa Gambling Task (Bechara et al., 1994), the Behavioral Investment Allocation Strategy (Kuhnen \& Knutson, 2005), and the Balloon Analogue Risk Task (Lejuez et al., 2002). Small to medium effects of aging have been observed within these three paradigms (Mata et al., 2011). To what extent do efficient decisions in these paradigms require processes that are subject to cognitive aging? For instance, it has been suggested that in the Iowa Gambling Task the key to good performance is the ability to reverse a learned contingency, which involves inhibition of a previously rewarded response and shifting to a newly rewarded response (Fellows \& Farah, 2005). Are age-related reversal learning deficits related to age differences in decision making? Clearly, a better understanding of decision making in older age will require the analysis of more than one experienced-based paradigm, and comparative modeling of these paradigms to reveal the common and distinct processes recruited by the aging mind.

\subsection{Conclusions}

In many domains, people lack the luxury of convenient descriptions of the probabilistic structure of their choice options and need to make decisions from experience. We used a sampling paradigm and variations thereof to investigate whether younger and older adults arrived at different decisions-and whether they arrived differently at those decisions. In our studies, cognitive aging (as indicated by, e.g., lower fluid abilities) predominantly did not coincide with profound age differences in decision making.
Of course, this result concerns just one of the many experimental paradigms used in decision making. In the future, the challenge is to understand how results from different paradigms fit together to form a more comprehensive picture of the decision-making performance of older people. After all, some of them run the world.

\section{Acknowledgements}

This work was supported by the Stiftung Suzanne und Hans Biäsch zur Förderung der Angewandten Psychologie. We thank Susannah Goss and Laura Wiles for editing the manuscript, and the Swiss National Science Foundation for a grant to the third author (CRSII1_136227).

\section{Appendix A}

\section{A.1. Specification of models implemented in Study 2}

All models were separately fitted to each participant's decisions using log-likelihood techniques. To estimate the parameters of each of the different models, we first used a genetic algorithm (with a population size of $N=200$ over 100 generations, with elitism set to $N=40$ and a mutation chance of .005; Lucasius \& Kateman, 1993), followed by a Nelder-Mead simplex optimization using the best fitting parameters from the genetic algorithm as a starting point (Nelder \& Mead, 1965). Both optimization algorithms were implemented in R, version 3.0.2 (R Core Team, 2014).

\section{A.1.1. Choice rules}

To be able to fit the models using log-likelihood techniques (which require probabilistic model predictions), as well as for reasons of comparability across the models, we used the same exponential choice rule in all models described below (Luce, 1959; Rieskamp, 2008). A choice of decision option $a$ over decision option $b$ is predicted by

$p(a, b)=\frac{e^{\theta \cdot S V(a)}}{e^{\theta \cdot S V(a)}+e^{\theta \cdot S V(b)}}$,

where $\operatorname{SV}(a)$ is the subjective value of decision option $a$ (resulting from CPT's prediction or from one of the learning models' final evaluation at the end of the sampling process), and $\theta$ is a free choice sensitivity parameter.

To rule out the possibility that the free choice sensitivity parameter systematically influenced the models' parameter estimates (because some of the models' parameter estimates may not be completely independent from the choice sensitivity parameter), we also implemented all models with the choice sensitivity parameter fixed to 1. As expected, the fit of these models decreased, but on the whole the parameter estimates were not systematically different. Therefore, we only report the model implementations with the choice rule involving a free sensitivity parameter.

\section{A.1.2. Cumulative prospect theory (CPT)}

According to CPT (Tversky \& Kahneman, 1992), choices can be described by a value function and a probability 
weighting function, with different parameterizations for gains and losses. Specifically, CPT assumes that outcomes are weighted according to

$$
v(x)=\left\{\begin{array}{ll}
x^{\alpha} & \text { if } x \geqslant 0 \\
-\lambda(-x)^{\beta} & \text { if } x<0
\end{array},\right.
$$

where $x$ represents either a positive or a negative outcome, $\alpha$ a weighting parameter for gains, $\beta$ a weighting parameter for losses, and $\lambda$ a parameter to model loss aversion. Here, we report a constrained version of the value function with $\alpha=\beta$ (note that we have also tested a version in which $\alpha$ and $\beta$ have been estimated separately with $\lambda$ fixed to 1 , but this version performed substantially worse). We implemented two different weighting functions proposed by Prelec (1998). In Prelec-I, the probabilities of the outcomes are weighted according to

$w^{+}(p)=e^{-(-\ln p)^{\gamma^{+}}}$

where $w^{+}$is the weighted probability for positive outcomes, using $\gamma^{+}$as a free weighting parameter. Equivalently, $w^{-}$is the weighted probability for negative outcomes, using $\gamma^{-}$as a free weighting parameter. In Prelec-II, the probabilities of the outcomes are weighted according to

$w^{+}(p)=e^{-\delta^{+}(-\ln p)^{\gamma^{+}}}$,

with the only difference to Prelec-I being the additional parameter $\delta^{+}$, which governs the elevation of the weighting function. Prelec-I is nested within Prelec-II (i.e., it corresponds to Prelec-II with $\delta^{+}$set to 1 ), so the estimated parameters can be directly compared with each other, even if some participants are better described by Prelec-I and others by Prelec-II.

We implemented CPT using Prelec-I and the same $\gamma$ parameters for gains and losses ("PR1"), using Prelec-I and different $\gamma$ parameters for gains and losses ("PR1g"), using Prelec-II and the same $\gamma$ and $\delta$ for gains and losses ("PR2"), using Prelec-II and the same $\gamma$ but different $\delta$ parameters for gains and losses ("PRd"), using Prelec-II and the same $\delta$ but different $\gamma$ parameters for gains and losses ("PR2g"), and using Prelec-II using different $\gamma$ and different $\delta$ parameters for gains and losses ("PR2gd"). We implemented all these models with the choice rule A1 either with a free or a fixed sensitivity parameter, resulting in a total of 12 different versions of CPT.

\section{A.1.3. Value-updating model (VUM)}

According to the VUM (Hau et al., 2008; Hertwig et al., 2006), decision makers update their subjective value of an option after each draw from it according to

$S V_{j, t}=\left(1-\omega_{j, t}\right) S V_{j, t-1}+\omega_{j, t} x_{j, t}$,

where $S V_{j, t}$ represents the subjective value of the choice option $j$ at sample $t$, and $\omega_{j, t}$ represents the weight attributed to the outcome $x$ that was sampled from option $j$ at trial $t$. This weight is determined by $\omega_{j, t}=(1 / t)^{\varphi}$, where $\varphi$ is a free parameter that captures whether more weight is attributed to outcomes occurring early or late in the sampling sequence. When $\varphi=1$, all outcomes receive the same weight and the subjective value of the option equals the mean of all outcomes. When $\varphi<1$, outcomes sampled more recently in the sequence receive more weight; thus, the subjective value will describe a recency effect. When $\varphi>1$, outcomes sampled earlier in the sequence receive more weight; thus, the subjective value will describe a primacy effect.

\section{A.1.4. Decay-reinforcement model (DECAY)}

According to the decay-reinforcement learning model (Erev \& Roth, 1998), decision makers' subjective values of a decision option decay constantly from draw to draw. The decay and updating processes of an option's subjective value occur according to

$S V_{j, t}=\varphi \cdot S V_{j, t-1}+x_{j, t}$,

where $S V_{j, t}$ is the subjective value of option $j$ at trial $t, x_{j, t}$ is the outcome that was sampled from option $j$ at trial $t$ (and is 0 if option $j$ was not sampled at that trial $t$ ), and $\varphi$ is the decay parameter. In other words, the subjective value of an option decays no matter whether it was sampled at a particular trial or not.

\section{A.1.5. Delta-rule learning model (DELTA)}

The DELTA model (Busemeyer \& Myung, 1992; Sutton \& Barto, 1998) assumes that decision makers update their subjective values of options only when they are actually sampled, and that these subjective values otherwise stay constant. The updating of the subjective values occurs according to

$S V_{j, t}=(1-\varphi) \cdot S V_{j, t-1}+\varphi \cdot x_{j, t}$,

where $S V_{j, t}$ is the subjective value of option $j$ at trial $t, x_{j, t}$ is the outcome that was sampled from option $j$ at trial $t$, and $\varphi$ is the learning rate parameter.

\section{A.1.6. Reinforcement learning model with decreasing learning rate ( $R L-D E C R)$}

This reinforcement learning model assumes that the learning rate decreases from trial to trial, resulting in a more fine-grained adjustment of an option's subjective value as learning experience increases (Yechiam \& Busemeyer, 2005). The options' subjective values are updated according to

$S V_{j, t}=S V_{j, t-1}+\frac{1}{t_{j}^{\varphi}} \cdot x_{j, t}$,

where $S V_{j, t}$ is the subjective value of option $j$ at trial $t, x_{j, t}$ is the outcome that was sampled from option $j$ at trial $t$, and $\varphi$ is the learning rate. The impact of this learning rate on the newly sampled outcome $x_{j, t}$ decreases as $t_{j}$ increases.

\section{A.1.7. Instance-based learning model (IBLM)}

The IBLM (Gonzalez \& Dutt, 2011; Gonzalez, Dutt, \& Lejarraga, 2011) assumes that the sampled outcomes are stored as instances in memory (e.g., "sample option $A$ and observe the outcome 3 "). Whenever a previously sampled outcome is sampled from the same decision option again, the respective instance is re-activated in memory, while the activation of the other instances decay from trial to trial. The model predicts that a choice is made based on 
Table A1

Correlations between younger and older adults' cognitive abilities and the estimated parameter values of the best performing CPT version.

\begin{tabular}{|c|c|c|c|c|c|c|}
\hline & \multicolumn{3}{|l|}{ Younger adults } & \multicolumn{3}{|l|}{ Older adults } \\
\hline & Fluid abilities & Crystallized abilities & Numeracy & Fluid abilities & Crystallized abilities & Numeracy \\
\hline \multicolumn{7}{|c|}{$C P T$} \\
\hline$\alpha$ & .03 & -.46 & .17 & -.14 & .11 & .27 \\
\hline$\beta$ & .03 & -.46 & .17 & -.14 & .1 & .27 \\
\hline$\lambda$ & -.1 & 0 & -.18 & .03 & -.11 & -.1 \\
\hline$\gamma+$ & -.02 & .27 & .03 & .17 & .16 & .1 \\
\hline$\gamma-$ & .16 & .24 & -.02 & .19 & .15 & .09 \\
\hline$\delta+$ & 0 & 0 & 0 & .04 & .03 & .09 \\
\hline$\delta-$ & 0 & 0 & 0 & 0 & -.04 & .01 \\
\hline$\theta$ & -.01 & .38 & .05 & .18 & 0 & -.01 \\
\hline \multicolumn{7}{|c|}{ Delta-rule learning model } \\
\hline$\varphi$ & .05 & -.4 & -.19 & -.33 & -.38 & -.38 \\
\hline$\theta$ & .29 & .11 & .35 & .18 & .56 & .51 \\
\hline
\end{tabular}

Note: Credible correlations are printed in bold.

Table A2

Mean levels and variability (SDs) of participants' emotional states (0-100 scale) across sessions in Study 2 (the values, including the differences, represent the modes of the posterior distributions obtained from Bayesian $t$ tests).

\begin{tabular}{|c|c|c|c|c|c|}
\hline \multirow[t]{2}{*}{ Characteristic } & \multicolumn{2}{|c|}{ Age group } & \multicolumn{3}{|c|}{ Statistic } \\
\hline & Young & Old & $\Delta$ & 95\% HDI & $d$ \\
\hline \multicolumn{6}{|c|}{ Mean levels of affect } \\
\hline Happy & 59.2 & 63.8 & 4.7 & -2.9 to 12.2 & .31 \\
\hline Afraid & 6.1 & 1.6 & -4.5 & -9.4 to -.2 & .70 \\
\hline Sad & 17.6 & 11.0 & -6.7 & -14.4 to 1.1 & .42 \\
\hline Angry & 15.5 & 11.5 & -4.1 & -10.8 to 2.7 & .34 \\
\hline Positive arousal & 41.3 & 54.0 & 12.7 & 3.5 to 21.8 & .66 \\
\hline Negative arousal & 20.0 & 15.6 & -4.5 & -12.1 to 3.4 & .30 \\
\hline Tired & 47.7 & 29.4 & -18.3 & -27.5 to -8.8 & .96 \\
\hline Time pressure & 30.8 & 20.3 & -10.5 & -20.2 to -1.0 & .55 \\
\hline \multicolumn{6}{|l|}{ Variability in affect } \\
\hline Happy & 15.9 & 13.4 & -2.4 & -6.0 to 1.2 & .35 \\
\hline Afraid & 12.7 & 9.8 & -5.2 & -10.2 to -.3 & .51 \\
\hline Sad & 17.3 & 11.5 & -5.8 & -10.6 to -1.0 & .58 \\
\hline Angry & 17.6 & 14.9 & -2.7 & -7.5 to 2.2 & .26 \\
\hline Positive arousal & 20.9 & 17.0 & -3.9 & -7.9 to .1 & .50 \\
\hline Negative arousal & 19.0 & 16.7 & -2.3 & -7.0 to 2.6 & .22 \\
\hline Tired & 25.8 & 21.9 & -3.9 & -8.6 to .8 & .41 \\
\hline Time pressure & 24.4 & 18.7 & -5.7 & -10.8 to -.7 & .55 \\
\hline
\end{tabular}

Note: Credible differences (with highest density intervals that do not include 0 ) are printed in bold.

the decision options' "blended values," which are assumed to be a weighted sum of the outcomes associated with the stored instances and the respective probabilities that these instances can be retrieved, as defined by

$V_{j}=\sum_{i=1}^{n} p_{i} x_{i}$

where $V_{j}$ is the blended value of option $j, p_{i}$ is the probability of retrieving instance $i$ from memory, and $x_{i}$ is the outcome associated with instance $i$. The probability of retrieving an instance $i$ is a function of its activation relative to the activation of all other instances according to

$p_{i, t}=\frac{e^{A_{i, t /(\sigma \cdot \sqrt{2})}}}{\sum_{j} e^{A_{i, t / \sigma \cdot \sqrt{2}}}}$,

where $A_{i, t / t}$ is the activation of instance $i$ at trial $t$ (note that trial $t$ is always the last sample in our case, because we are only concerned about modeling the final choice), and $\sigma$ is a noise parameter. The core assumption of the IBLM is that the activation of an instance depends on its frequency of occurrence as well as on its temporal distance from the last activation, as proposed originally in ACT-R (Anderson \& Lebiere, 1998, 2003). In a simplified version, the activation of an instance $i$ occurs according to

$A_{i, t}=\ln \left(\sum_{t_{i \varepsilon\{1, \ldots, t-1\}}}\left(t-t_{i}\right)^{-d}\right)+\sigma \cdot \ln \left(\frac{1-\gamma_{i, t}}{\gamma_{i, t}}\right)$,

where $d$ is a decay parameter and $\sigma$ a noise parameter modeling imprecision in retrieving an instance from memory; $\gamma_{i, t}$ is a random draw from a uniform distribution $U(0,1)$.

The stochastic components of the IBLM (i.e., the parameters that capture noise in the memory processes) vary from trial to trial and are therefore problematic for 
log-likelihood fitting on the level of individual participants, because exactly the same parameter combinations can lead to substantially different choice predictions. Therefore, we implemented a version of the IBLM in which we fitted and held constant the $\sigma$ and the $\gamma$ within each participant ("IBLM-G"), as well as a version in which we fitted and held constant the $\sigma$ parameter, but omitted the $\gamma$ parameter ("IBLM").

\section{References}

Agarwal, S., Driscoll, J., Gabaix, X., \& Laibson, D. (2009). The age of reason: Financial decisions over the lifecycle. Brookings Papers on Economic Activity, 51-117. http://dx.doi.org/10.1353/eca.0.0067.

Anderson, J. R., \& Lebiere, C. (1998). The atomic components of thought. Mahwah, NJ: Lawrence Erlbaum.

Anderson, J. R., \& Lebiere, C. (2003). The Newell Test for a theory of cognition. Behavioral and Brain Sciences, 26, 587-601. http:// dx.doi.org/10.1017/S0140525X0300013X.

Barron, G., \& Erev, I. (2003). Small feedback-based decisions and their limited correspondence to description-based decisions. Journal of Behavioral Decision Making, 16, 215-233. http://dx.doi.org/10.1002/ bdm.443.

Bechara, A., Damasio, A. R., Damasio, H., \& Anderson, S. W. (1994). Insensitivity to future consequences following damage to human prefrontal cortex. Cognition, 50, 7-15. http://dx.doi.org/10.1016/ 0010-0277(94)90018-3.

Boyle, P. A., Yu, L., Buchman, A. S., Laibson, D. I., \& Bennett, D. A. (2011). Cognitive function is associated with risk aversion in communitybased older persons. BMC Geriatrics, 11, 53. http://dx.doi.org/10.1186/ 1471-2318-11-53.

Busemeyer, J. R., \& Myung, I. J. (1992). An adaptive approach to human decision making: Learning theory, decision theory, and human performance. Journal of Experimental Psychology: General, 121, 177-194. http://dx.doi.org/10.1037/0096-3445.121.2.177.

Bush, R. R., \& Mosteller, F. (1955). Stochastic models for learning. Oxford, England: John Wiley \& Sons.

Coall, D. A., \& Hertwig, R. (2010). Grandparental investment: Past, present, and future. Behavioral and Brain Sciences, 33, 1-19.

Del Missier, F., Mäntylä, T., Hansson, P., Bruine de Bruin, W., Parker, A. M., \& Nilsson, L.-G. (2013). The multifold relationship between memory and decision making: An individual-differences study. Journal of Experimental Psychology: Learning, Memory, and Cognition, 39, 1344-1364. http://dx.doi.org/10.1037/a0032379.

Denburg, N. L., Tranel, D., \& Bechara, A. (2005). The ability to decide advantageously declines prematurely in some normal older persons. Neuropsychologia, 43, 1099-1106. http://dx.doi.org/10.1016/ j.neuropsychologia.2004.09.012.

Eppinger, B., Hämmerer, D., \& Li, S.-C. (2011). Neuromodulation of reward-based learning and decision making in human aging. Annals of the New York Academy of Sciences, 1235, 1-17. http://dx.doi.org/ 10.1111/j.1749-6632.2011.06230.x.

Erev, I., Ert, E., Roth, A. E., Haruvy, E., Herzog, S. M., Hau, R., et al. (2010). A choice prediction competition: Choices from experience and from description. Journal of Behavioral Decision Making, 23, 15-47. http:// dx.doi.org/10.1002/bdm.683.

Erev, I., \& Roth, A. E. (1998). Predicting how people play games: Reinforcement learning in experimental games with unique, mixed strategy equilibria. The American Economic Review, 88, $848-881$.

Estes, W. K. (1950). Toward a statistical theory of learning. Psychological Review, 57, 94-107. http://dx.doi.org/10.1037/h0058559.

Fellows, L. K., \& Farah, M. J. (2005). Different underlying impairments in decision-making following ventromedial and dorsolateral frontal lobe damage in humans. Cerebral Cortex, 15, 58-63. http://dx.doi.org/ $10.1093 /$ cercor/bhh108.

Fox, C. R., \& Hadar, L. (2006). "Decisions from experience" = sampling error + prospect theory: Reconsidering Hertwig, Barron, Weber \& Erev (2004). Judgment and Decision Making, 1, 159-161.

Frey, R., Hertwig, R., \& Rieskamp, J. (2014). Fear shapes information acquisition in decisions from experience. Cognition, 132, 90-99. http://dx.doi.org/10.1016/j.cognition.2014.03.009.

Goldberg, L. R. (1970). Man versus model of man: A rationale, plus some evidence, for a method of improving on clinical inferences. Psychological Bulletin, 73, 422. http://dx.doi.org/10.1037/h0029230.
Gonzalez, C., \& Dutt, V. (2011). Instance-based learning: Integrating sampling and repeated decisions from experience. Psychological Review, 118, 523-551. http://dx.doi.org/10.1037/a0024558.

Gonzalez, C., Dutt, V., \& Lejarraga, T. (2011). A loser can be a winner: Comparison of two instance-based learning models in a market entry competition. Games, 2, 136-162. http://dx.doi.org/10.3390/ g2010136.

Hadfield, J. D. (2010). MCMC methods for multi-response generalized linear mixed models: The MCMCglmm R Package. Journal of Statistical Software, 33, 1-22.

Hasher, L., \& Zacks, R. T. (1984). Automatic processing of fundamental information: The case of frequency of occurrence. American Psychologist, 39, 1372-1388. http://dx.doi.org/10.1037/0003066X.39.12.1372.

Hau, R., Pleskac, T. J., Kiefer, J., \& Hertwig, R. (2008). The descriptionexperience gap in risky choice: The role of sample size and experienced probabilities. Journal of Behavioral Decision Making, 21, 493-518. http://dx.doi.org/10.1002/bdm.598.

Hertwig, R., Barron, G., Weber, E. U., \& Erev, I. (2004). Decisions from experience and the effect of rare events in risky choice. Psychological Science, 15, 534-539. http://dx.doi.org/10.1111/j.0956-7976.2004. 00715.x.

Hertwig, R., Barron, G., Weber, E. U., \& Erev, I. (2006). Decisions from experience: Sampling and updating of information. In K. Fiedler \& P. Juslin (Eds.), Information sampling and adaptive cognition. New York, NY: Cambridge University Press.

Hertwig, R., \& Erev, I. (2009). The description-experience gap in risky choice. Trends in Cognitive Sciences, 13, 517-523. http://dx.doi.org/ 10.1016/j.tics.2009.09.004.

Hertwig, R. (2015). Decisions from experience. In G. Keren \& G. Wu (Eds.), Handbook of judgment and decision making. Blackwell.

Hertwig, R., \& Pleskac, T. J. (2010). Decisions from experience: Why small samples? Cognition, 115, 225-237. http://dx.doi.org/10.1016/ j.cognition.2009.12.009.

Hills, T. T., Noguchi, T., \& Gibbert, M. (2013). Information overload or search-amplified risk? Set size and order effects on decisions from experience. Psychonomic Bulletin \& Review. http://dx.doi.org/10.3758/ s13423-013-0422-3.

Hofer, S. M., \& Sliwinski, M. J. (2001). Understanding ageing. Gerontology, 47, 341-352. http://dx.doi.org/10.1159/000052825.

Hogarth, R. M., \& Einhorn, H. J. (1992). Order effects in belief updating: The belief-adjustment model. Cognitive Psychology, 24, 1-55. http:// dx.doi.org/10.1016/0010-0285(92)90002-J.

Howard, C. (2013). The world's most powerful people 2013. Forbes. <http:// www.forbes.com/sites/carolinehoward/2013/10/30/the-worldsmost-powerful-people-2013/> Retrieved 06.06.14.

Kovalchik, S., Camerer, C. F., Grether, D. M., Plott, C. R., \& Allman, J. M. (2005). Aging and decision making: A comparison between neurologically healthy elderly and young individuals. Journal of Economic Behavior \& Organization, 58, 79-94. http://dx.doi.org/ 10.1016/j.jebo.2003.12.001.

Kruschke, J. K. (2010). Bayesian data analysis. Wiley Interdisciplinary Reviews: Cognitive Science, 1, 658-676. http://dx.doi.org/10.1002/ wcs.72.

Kruschke, J. K. (2011). Bayesian assessment of null values via parameter estimation and model comparison. Perspectives on Psychological Science, 6, 299-312. http://dx.doi.org/10.1177/1745691611406925.

Kruschke, J. K. (2013). Bayesian estimation supersedes the t test. Journal of Experimental Psychology: General, 142, 573-603. http://dx.doi.org/ $10.1037 / \mathrm{a} 0029146$.

Kuhnen, C. M., \& Knutson, B. (2005). The neural basis of financial risk taking. Neuron, 47, 763-770. http://dx.doi.org/10.1016/ j.neuron.2005.08.008.

Lehrl, S. (1977). Mehrfachwahl-Wortschatz-Intelligenztest: MWT-B. Perimed-Verlag Straube.

Lejarraga, T., Hertwig, R., \& Gonzalez, C. (2012). How choice ecology influences search in decisions from experience. Cognition, 124, 334-342. http://dx.doi.org/10.1016/j.cognition.2012.06.002.

Lejuez, C. W., Read, J. P., Kahler, C. W., Richards, J. B., Ramsey, S. E., Stuart, G. L., et al. (2002). Evaluation of a behavioral measure of risk taking: The Balloon Analogue Risk Task (BART). Journal of Experimental Psychology: Applied, 8, 75-84. http://dx.doi.org/10.1037/1076898X.8.2.75

Lewandowsky, S., \& Farrell, S. (2010). Computational modeling in cognition: Principles and practice. Thousand Oaks, CA: Sage.

Li, Y., Baldassi, M., Johnson, E. J., \& Weber, E. U. (2013). Complementary cognitive capabilities, economic decision making, and aging. Psychology and Aging, 28, 595-613. http://dx.doi.org/10.1037/ a0034172. 
Li, S.-C., Lindenberger, U., Hommel, B., Aschersleben, G., Prinz, W., \& Baltes, P. B. (2004). Transformations in the couplings among intellectual abilities and constituent cognitive processes across the life span. Psychological Science, 15, 155-163. http://dx.doi.org/ 10.1111/j.0956-7976.2004.01503003.x.

Lipkus, I. M., Samsa, G., \& Rimer, B. K. (2001). General performance on a numeracy scale among highly educated samples. Medical Decision Making, 21, 37-44. http://dx.doi.org/10.1177/0272989X0102100105.

Lucasius, C. B., \& Kateman, G. (1993). Understanding and using genetic algorithms Part 1. Concepts, properties and context. Chemometrics and Intelligent Laboratory Systems, 19, 1-33. http://dx.doi.org/10.1016/ 0169-7439(93)80079-W.

Luce, R. D. (1959). Individual choice behavior. New York: Wiley.

March, J. G. (1996). Learning to be risk averse. Psychological Review, 103, 309. http://dx.doi.org/10.1037/0033-295X.103.2.309.

Marschner, A., Mell, T., Wartenburger, I., Villringer, A., Reischies, F. M., \& Heekeren, H. R. (2005). Reward-based decision-making and aging. Brain Research Bulletin, 67, 382-390. http://dx.doi.org/10.1016/ j.brainresbull.2005.06.010.

Martin, A. D., Quinn, K. M., \& Park, J. H. (2011). MCMCpack: Markov chain Monte Carlo in R. Journal of Statistical Software, 42, 1-21.

Mata, R., \& Hertwig, R. (2011). How to model age-related motivational reorientations in risky choice. Human Development, 54, 368-375. http://dx.doi.org/10.1159/000334943.

Mata, R., Josef, A. K., Samanez-Larkin, G. R., \& Hertwig, R. (2011). Age differences in risky choice: A meta-analysis. Annals of the New York Academy of Sciences, 1235, 18-29. http://dx.doi.org/10.1111/j.17496632.2011.06200.x.

Mata, R., \& Nunes, L. (2010). When less is enough: Cognitive aging, information search, and decision quality in consumer choice. Psychology and Aging, 25, 289-298. http://dx.doi.org/10.1037/ a0017927.

Mata, R., Pachur, T., von Helversen, B., Hertwig, R., Rieskamp, J., \& Schooler, L. (2012). Ecological rationality: A framework for understanding and aiding the aging decision maker. Frontiers in Neuroscience, 6. http://dx.doi.org/10.3389/fnins.2012.00019.

Mata, R., Schooler, L. J., \& Rieskamp, J. (2007). The aging decision maker: Cognitive aging and the adaptive selection of decision strategies. Psychology and Aging, 22, 796-810. http://dx.doi.org/10.1037/08827974.22.4.796.

Mata, R., von Helversen, B., \& Rieskamp, J. (2010). Learning to choose: Cognitive aging and strategy selection learning in decision making. Psychology and Aging, 25, 299-309. http://dx.doi.org/10.1037/ a0018923.

Morey, R. D., \& Rouder, J. N. (2011). Bayes factor approaches for testing interval null hypotheses. Psychological Methods, 16.

Nelder, J. A., \& Mead, R. (1965). A simplex method for function minimization. The Computer Journal, 7, 308-313. http://dx.doi.org/ 10.1093/comjnl/7.4.308.

Nilsson, L.-G., Adolfsson, R., Bäckman, L., de Frias, C. M., Molander, B., \& Nyberg, L. (2004). Betula: A prospective cohort study on memory, health and aging. Aging, Neuropsychology, and Cognition, 11, 134-148. http://dx.doi.org/10.1080/13825580490511026.

Park, D. C., Lautenschlager, G., Hedden, T., Davidson, N. S., Smith, A. D., \& Smith, P. K. (2002). Models of visuospatial and verbal memory across the adult life span. Psychology and Aging, 17, 299-320. http:// dx.doi.org/10.1037//0882-7974.17.2.299.

Peters, E., Hess, T. M., Västfjäll, D., \& Auman, C. (2007). Adult age differences in dual information processes: Implications for the role of affective and deliberative processes in older adults' decision making. Perspectives on Psychological Science, 2, 1-23. http://dx.doi.org/ 10.1111/j.1745-6916.2007.00025.x.

Prelec, D. (1998). The probability weighting function. Econometrica, 66, 497-527. http://dx.doi.org/10.2307/2998573.

Queen, T. L., Hess, T. M., Ennis, G. E., Dowd, K., \& Grühn, D. (2012). Information search and decision making: Effects of age and complexity on strategy use. Psychology and Aging, 27, 817-824. http://dx.doi.org/10.1037/a0028744.

$\mathrm{R}$ Core Team (2014). R: A language and environment for statistical computing. Vienna, Austria. <http://www.R-project.org>.
Raftery, A. E. (1995). Bayesian model selection in social research Sociological Methodology, 25, 111-163. http://dx.doi.org/10.2307/ 271063.

Rakow, T., Demes, K. A., \& Newell, B. R. (2008). Biased samples not mode of presentation: Re-examining the apparent underweighting of rare events in experience-based choice. Organizational Behavior and Human Decision Processes, 106, 168-179. http://dx.doi.org/10.1016/ j.obhdp.2008.02.001.

Rakow, T., Newell, B. R., \& Zougkou, K. (2010). The role of working memory in information acquisition and decision making: Lessons from the binary prediction task. The Quarterly Journal of Experimental Psychology, 63, 1335-1360. http://dx.doi.org/10.1080/ 17470210903357945.

Rieskamp, J. (2008). The probabilistic nature of preferential choice. Journal of Experimental Psychology: Learning, Memory, and Cognition, 34, 1446-1465. http://dx.doi.org/10.1037/a0013646.

Röcke, C., Li, S.-C., \& Smith, J. (2009). Intraindividual variability in positive and negative affect over 45 days: Do older adults fluctuate less than young adults? Psychology and Aging, 24, 863-878. http://dx.doi.org/ $10.1037 / \mathrm{a} 0016276$.

Rouder, J. N., Speckman, P. L., Sun, D., Morey, R. D., \& Iverson, G. (2009). Bayesian t tests for accepting and rejecting the null hypothesis. Psychonomic Bulletin \& Review, 16, 225-237.

Samanez-Larkin, G. R., Wagner, A. D., \& Knutson, B. (2011). Expected value information improves financial risk taking across the adult life span. Social Cognitive and Affective Neuroscience, 6, 207-217. http:// dx.doi.org/10.1093/scan/nsq043.

Schaie, K. W. (2012). Developmental influences on adult intelligence: The Seattle longitudinal study. New York, NY: Oxford University Press.

Shing, Y. L., Werkle-Bergner, M., Li, S.-C., \& Lindenberger, U. (2008). Associative and strategic components of episodic memory: A lifespan dissociation. Journal of Experimental Psychology: General, 137, 495-513. http://dx.doi.org/10.1037/0096-3445.137.3.495.

Spaniol, J., \& Wegier, P. (2012). Decisions from experience: Adaptive information search and choice in younger and older adults. Frontiers in Decision Neuroscience, 6. http://dx.doi.org/10.3389/ fnins.2012.00036.

Sutton, R. S., \& Barto, A. G. (1998). Reinforcement learning: An introduction. Cambridge, MA: The MIT Press.

The capitol's age pyramid: A graying congress (2010). The Wall Street Journal. <http://online.wsj.com/public/resources/documents/infoCONGRESS_AGES_1009.html>.

Tversky, A., \& Kahneman, D. (1992). Advances in prospect theory: Cumulative representation of uncertainty. Journal of Risk and Uncertainty, 5, 297-323. http://dx.doi.org/10.1007/BF00122574.

Tymula, A., Rosenberg Belmaker, L. A., Ruderman, L., Glimcher, P. W., \& Levy, I. (2013). Like cognitive function, decision making across the life span shows profound age-related changes. Proceedings of the National Academy of Sciences, 110, 17143-17148. http://dx.doi.org/10.1073/ pnas.1309909110.

Unsworth, N., Heitz, R. P., Schrock, J. C., \& Engle, R. W. (2005). An automated version of the operation span task. Behavior Research Methods, 37, 498-505.

Wagenmakers, E.-J. (2007). A practical solution to the pervasive problems of p values. Psychonomic Bulletin E Review, 14, 779-804. http:// dx.doi.org/10.3758/BF03194105.

Weber, E. U., Shafir, S., \& Blais, A.-R. (2004). Predicting risk-sensitivity in humans and lower animals: Risk as variance or coefficient of variation. Psychological Review, 111, 430-445. http://dx.doi.org/ 10.1037/0033-295X.111.2.430.

Wechsler, D. (1981). Wechsler adult intelligence scale: Revised manual (WAIS-R). New York, NY: Psychological Corporation.

Yechiam, E., \& Busemeyer, J. R. (2005). Comparison of basic assumptions embedded in learning models for experience-based decision making. Psychonomic Bulletin \& Review, 12, 387-402. http://dx.doi.org/ 10.3758/BF03193783.

Zamarian, L., Sinz, H., Bonatti, E., Gamboz, N., \& Delazer, M. (2008). Normal aging affects decisions under ambiguity, but not decisions under risk. Neuropsychology, 22, 645-657. http://dx.doi.org/10.1037/ 0894-4105.22.5.645. 